\title{
PLANEJAMENTO E CONTROLE DA PRODUÇÃO COM EDUCAÇÃO AMBIENTAL: UM ESTUDO DE CASO EM UMA EMPRESA DO SEGMENTO QUÍMICO
}

OLIVEIRA NETO, Geraldo Cardoso de. Doutor em Engenharia da Produção. Professor e pesquisador do Programa de Mestrado em Engenharia da Produção da Universidade Nove de Julho - Uninove, Rua Francisco

Matarazzo, 612 CEP 05001-100, São Paulo/SP. Brasil. E-mail: geraldo.neto@ uninove.br.

VENDRAMETTO, Oduvaldo. Doutor em Engenharia de Produção pela Universidade de São Paulo - USP.

E-mail: oduvaldov@uol.com.br.

AZZOLINI JUNIOR, Walther. Doutor em Engenharia Mecânica - USP-São Carlos, professor-assistente da USP/São Carlos e pesquisador convidado do Grupo de Pesquisa em Gestão da Produção com ênfase no PCP-

PLACOP vinculado ao Departamento e ao Programa de Pós-Graduação em Engenharia de Produção da Universidade Federal de São Carlos - UFSCar.

BONILLA, Silvia H. Doutora em Ciências pela Universidade de São Paulo - USP, professora-titular da Universidade Paulista - Unip, Rua Bacelar, 1212 CEP 04026-002, São Paulo/SP. Brasil. E-mail: bonilla@unip.br.

\section{RESUMO}

Este artigo tem por objetivo abordar um estudo de caso de uma empresa química que adequou o sistema de Planejamento, Programação e Controle da Produção à Educação Ambiental. Com esse propósito dá ênfase à infraestrutura necessária, visando sensibilizar e disseminar a educação ambiental de maneira transversal para os funcionários operacionais e planejadores da produção, tornando possível formar ecotime para a disseminação dos conhecimentos em Educação Ambiental e desenvolvimento de projetos sustentáveis. É importante salientar que os dois planejadores de produção foram os principais agentes do ecotime na criação do plano de ação sobre a estruturação da manufatura limpa. O desenvolvimento do estudo de caso se deu por meio de entrevista semiestruturada e observação participante, que permitiram levantar os princípios, as práticas e os capacitadores da Manufatura Limpa que a organização adotou como objetivo de desempenho para competitividade. Também foi possível avaliar as vantagens econômicas e ambientais da implantação do projeto envolvendo o sequenciamento das tarefas no âmbito das funções de planejamento e controle. As vantagens ambientais foram mensuradas por meio do método Wuppertal (2008). Duas variáveis foram consideradas na medição dos resultados obtidos com a implantação: o volume de produção em litros e o custo por litro da principal matéria-prima. O aumento do volume de produção foi de $20 \%$ em litros e a redução do custo por litro, de $10,6 \%$.

Palavras-chave: Planejamento e Controle da Produção; Educação Ambiental; Produção enxuta; Estudo de caso; Segmento químico.

\begin{abstract}
This article presents the case study of the implementation of Production Planning and Control with environmental education in a chemical plant. For this purpose, it emphasizes the necessary infrastructure, to sensitize and disseminate environmental education in a transversal way for officials and planners operating in production, making it possible to form ecoteam for the dissemination of knowledge in environmental education and sustainable development projects. It is noteworthy that the two production planners were the main agents of ecoteam in creating the action plan for the structuring of cleaner production. Semi-structured interviews and participant observation were used for the development of the case study, allowing to raise the principles, practices and the Clean Manufacturing enablers that the organization has adopted as a performance goal for competitiveness. It was also possible to evaluate the economic and environmental advantages of implementing the project involving
\end{abstract}


the sequencing of tasks within the planning and control functions. The environmental benefits were measured by the Wuppertal (2008) method. Two variables were considered in the measurement of results obtained with the implementation: the production volume in liters and the cost per liter of the main raw material. The increasing of the amount of production was $20 \%$ in liters and the cost reduction, of $10.6 \%$ per liter.

Keywords: Production Planning and Control; Environmental Education; Lean production; Case study; Chemical segment.

\section{INTRODUÇão}

As estratégias competitivas de natureza corporativa e as estratégias de manufatura têm evoluído devido a questões relacionadas aos paradigmas da manufatura. Essa evolução transforma a organização e a adequação do trabalho, a partir das alterações que proporcionaram aos profissionais da área de Planejamento, Programação e Controle da Produção o aprimoramento das habilidades e competências ao longo dos anos. Contudo, as transformações ocorridas na forma de organização e adequação do trabalho foram direcionadas pelo mercado, fazendo com que os objetivos de desempenho da organização fossem alterados ao longo do tempo. Dessa forma, as organizações passam a considerar em sua estratégia novas práticas e princípios com o uso de ferramentas condizentes à realidade das organizações. Nesse contexto foi possível o aprimoramento das habilidades ao longo dos anos.

Este artigo tem por objetivo geral abordar um estudo de caso de uma empresa química que adequou o sistema de Planejamento, Programação e Controle da Produção à Educação Ambiental. Para isso, estabeleceu a infraestrutura necessária para o controle de suas operações e estruturou o projeto e o sistema de produção para transformá-lo em uma Manufatura Limpa. A organização identificou, por meio de entrevista semiestruturada e observação participante, a necessidade atual de mudança e a tendência do avanço do aprimoramento do processo de gerência de produção frente à sustentabilidade. Dessa forma, $\mathrm{o}$ presente artigo demonstra os princípios, as práticas e os capacitadores da Manufatura Limpa que a organização adotou como objetivo de desempenho para competitividade.

$\mathrm{Na}$ concepção deste artigo, considera-se a definição de paradigma sob a ótica das trajetórias tecnológicas, incorporando fortes prescrições sobre as direções da mudança técnica no sistema produtivo, em que ao longo dos anos ocorrem mudanças incrementais no conhecimento prático e teórico de know how, métodos, procedimentos e atividades, dispositivos físicos e equipamentos denotando progresso (DOSI, 2006). Segundo Godinho Filho (2004), para surgir um novo Paradigma Estratégico na Gestão da Manufatura (PEGEM) há uma dependência direta de (i) direcionadores, que são as condições de mercado que possibilitam, requerem ou facilitam a implantação do PEGEM, assim como de (ii) princípios caracterizados pelas ideias que fundamentam as empresas rumo aos PEGEM, de (iii) capacitadores, compostos de tecnologias, metodologias e ferramentas de gestão e de (iv) objetivos de desempenho para tomada de decisão (SLACK et al., 2007). Especificamente, propõe-se avaliar e comparar as vantagens econômicas e as vantagens ambientais nesse arranjo. Os ganhos ambientais foram calculados por meio do método Wuppertal (2008).

\section{REFERENCIAL TEÓRICO \\ Evolução do Paradigma Estratégico da Gestão da Manufatura para a Manufatura Limpa}

Nesta seção há a intenção de apresentar o caráter evolucionário da gestão da manufatura ao longo dos anos (Quadro 1). Verificou-se, por meio da revisão bibliográfica, que o direcionador de mercado é propulsor da competitividade, ele dita a adequação, isto é, a maneira pela qual se organiza o trabalho, não o bastante, como transforma as habilidades das pessoas envolvidas no processo.

Antes do século $\mathrm{XX}$, as empresas processavam produtos artesanais sem grande inserção de práticas 
de gestão na manufatura. Womack et al. (1992) relatam que a ManufaturaArtesanal foi um período caracterizado por força de trabalho altamente qualificada em projeto, produção e montagem, com a particularidade de empresas descentralizadas com baixo volume de produção.

Segundo Porto et al. (2004), é a partir do século XX que a sistemática da divisão econômica do trabalho passa a imperar no âmbito da Manufatura em Massa, como intuito de garantir um aumento de produtividade, a qual é intensamente incrementada. Godinho Filho (2004) revela que, nesse período, havia alta divisão do trabalho e alto grau de repetitividade com produção baseada no baixo custo que explorava as economias de escala.

Em 1960, há um grande crescimento do mercado automotivo, que exigia "alta qualidade e baixos custos", impulsionando as organizações a se tornarem mais enxutas (BUFFA, 1984). Womack \& Jones (1998) definem Manufatura Enxuta como uma nova abordagem, segundo a qual existe uma forma melhor de organizar e gerenciar os relacionamentos de uma empresa com os clientes, cadeia de fornecedores, desenvolvimento de produtos e operações de produção. O objetivo essencial é fazer mais commenos. Godinho Filho (2004) diz que a ênfase passou a ser na melhoria das operações, eliminação de desperdícios, retrabalhos e diminuição do setup das máquinas com o intuito de redução do tamanho do lote de produção e, consequentemente, com o aumento na variedade de produtos oferecidos aos clientes. Em 1970 as empresas evoluíram para a produção sem defeitos, com inovações nos processos e pontualidade de entrega.

A necessidade de pontualidade na entrega direcionou as organizações a implementarem uma série de métodos destinados a reduzir o tempo de resposta aos clientes (BLACKBURN, 1991a). A estratégia da gestão da Manufatura Responsiva enfatiza a redução do tempo de desenvolvimento de produto e de produção como fatores vitais para o aumento da competitividade de uma empresa (BOWER \& HOUT,
1988; BOOTH, 1996), a fim de tornar a manufatura mais atraente sob a ótica do consumidor (HANDFIELD, 1995).

As indústrias perceberam que não basta fabricar produtos padronizados; é preciso inserir Customização em Massa, passando da economia de escala para uma economia de escopo, de forma a permitir a disponibilização de múltiplos produtos a custos mais baixos do que poderiam ser conseguidos individualmente (GOLDHAR; JELINEK, 1983). As empresas perceberam que, reduzindo os ciclos de vida dos produtos e fragmentando a demanda, poderiam obter grande vantagem competitiva, caso tivessem a habilidade de agregar flexibilidade e velocidade ao sistema produtivo, tornando-o capaz de responder às incertezas de mercado e às variabilidades internas rapidamente e com menor custo (PINE, 1994).

Sendo assim, em 1991 surge a Manufatura ágil (GODINHO FILHO, 2004), para responder às incertezas de mercado de maneira rápida (GUNASEKARAN, 1999). Dessa forma, entendese que a Manufatura Ágil possui como objetivos principais: atender às necessidades dos clientes e responder a mudanças inesperadas de maneira correta e no tempo, permitindo explorar novas oportunidades de mercado (DE VOR et al., 1997; SHARIFI \& ZHANG, 1999).

A partir do ano 2000, os stakeholders passaram a influenciar a rede de suprimentos para a produção de bens e serviços com consciência ambiental, orientando a produção para a manufatura limpa. Nesse caminho, as organizações procuram sensibilizar os envolvidos por meio da Educação Ambiental, para adequar o sistema produtivo para princípios, práticas e capacitadores ambientais, como intuito de implantação da produção mais limpa e ecologia industrial. É importante salientar que, por um lado, a organização favorece a redução da poluição, apresentando vantagens ambientais; por outro, ganha em competitividade e vantagens econômicas (OLIVEIRA NETO et al. 2010). 
Planejamento e controle da produção...

\begin{tabular}{|c|c|c|c|}
\hline $\begin{array}{l}\text { Paradigma Estratégico da } \\
\text { Ges tão da Manufatura }\end{array}$ & Direcionador de Mercado & Necessidade de adequação & Habi lidades \\
\hline $\begin{array}{l}\text { Manufatura artes anal } \\
\text { An terior ao século XX }\end{array}$ & $\begin{array}{l}\text { Partici pação do cliente no } \\
\text { proj eto }\end{array}$ & $\begin{array}{c}\text { Des centralização/ Baixa } \\
\text { Produti vidad e }\end{array}$ & Qualificado em proj eto \\
\hline $\begin{array}{l}\text { Manufatura em Massa } \\
\text { Início do século XX }\end{array}$ & $\begin{array}{l}\text { Preço bai xo/ Produtos } \\
\text { padronizados }\end{array}$ & Produti vidade/ Custo & Especialista \\
\hline $\begin{array}{l}\text { Manufatura Enxuta da década } \\
\text { de } 1950 \text { a década de } 1970\end{array}$ & $\begin{array}{l}\text { Qualidade/ Produ tos } \\
\text { diversi ficados }\end{array}$ & $\begin{array}{l}\text { Desperdícid Qu alidade/ } \\
\text { Trei nam ento }\end{array}$ & $\begin{array}{c}\text { Novas técnicas administrativas e } \\
\text { nova forma de organi zação } \\
\text { industrial }\end{array}$ \\
\hline $\begin{array}{l}\text { Manufatura Res ponsiva } \\
\text { Surge em } 1987\end{array}$ & $\begin{array}{c}\text { Prazo de entrega em curto } \\
\text { prazo }\end{array}$ & Tempo / Flexibilidade & Responsi vidad e / Adaptabilidade \\
\hline $\begin{array}{c}\text { Customi zação em Massa } \\
\text { Surge em } 1987\end{array}$ & $\begin{array}{c}\text { Produtos com } \\
\text { especificidades dos } \\
\text { clientes no curto prazo }\end{array}$ & $\begin{array}{c}\text { Cust omização / Personalização/ } \\
\text { Preços Baixos / Flexibili dade / } \\
\text { Produti vidade }\end{array}$ & Customi zação \\
\hline $\begin{array}{l}\text { Manufatura ágil } \\
\text { Surge em } 1991\end{array}$ & $\begin{array}{l}\text { Resposta a mu danças } \\
\text { rápidas de mercado }\end{array}$ & $\begin{array}{l}\text { Incert ezas e mudanças con stant es/ } \\
\text { Tecnolo gia avançada / Qual idade }\end{array}$ & $\begin{array}{c}\text { Resposta rápida e enfrentar } \\
\text { desafios }\end{array}$ \\
\hline $\begin{array}{c}\text { Manuf atura Limpa a partir do } \\
\text { ano } 2000 \text { até atual }\end{array}$ & $\begin{array}{l}\text { Imagem da empresa } \\
\text { Socioambiental - } \\
\text { Marketing Verde e } \\
\text { ISO } 14000\end{array}$ & $\begin{array}{l}\text { Produ ção Mai s Limpa/ eficiên cia } \\
\text { ecológica/ Anális e do Ci clo de } \\
\text { Vida/ Ecologia Industrial/ Cadeia } \\
\text { de Suprimentos Verde/ Logística } \\
\text { Reversa/ P\&D de pro dutos } \\
\text { ambiental mente corretos }\end{array}$ & Educação Ambiental \\
\hline
\end{tabular}

Quadro 1 - Necessidades de adaptação e habilidades frente ao surgimento de paradigmas no sistema produtivo ao longo dos anos.

Fonte: Adaptado de Godinho Filho (2004).

Planejamento, Programação e Controle da Produção com Educação Ambiental (PPCPEA)

Nesta seção será conceituado o processo de infraestrutura e estrutura do PPCPEA (Figura 1). É importante ressaltar a necessidade de considerar as questões ambientais no PCP de maneira flexível e adaptativa ao sistema produtivo, permitindo estabelecer mudanças incrementais na programação da produção, visando resolver problemas ambientais (YUKSEL, 2007). 


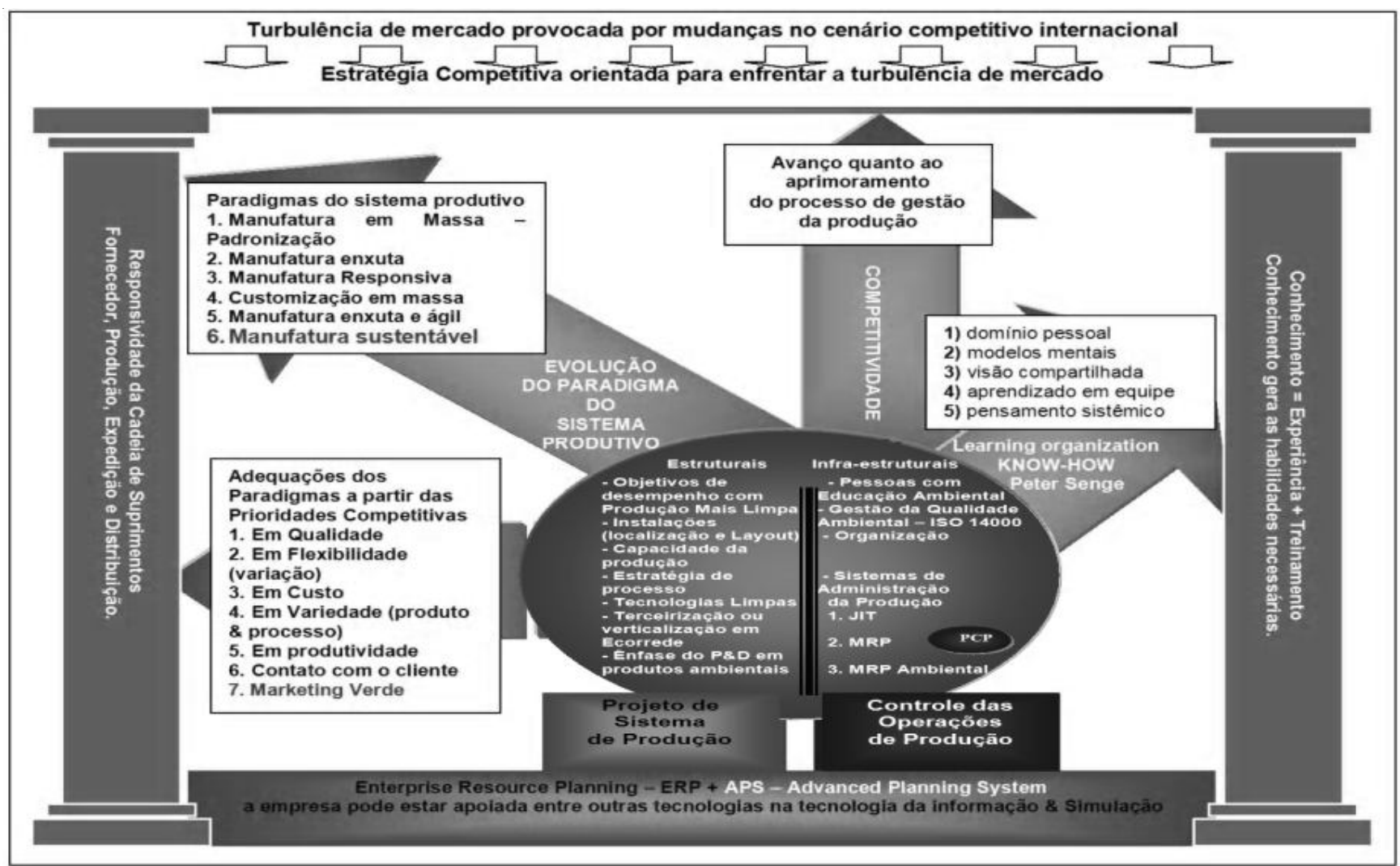

Figura 1 - Implementação do novo PEGEM no sistema produtivo.

Fonte: Oliveira Neto et al. (2010).

Entende-se por infraestrutura o conjunto de elementos que enquadram e suportam toda a estrutura da manufatura (AZZOLINI, 2004). Os elementos infraestruturais do PCPEA são apresentados no Quadro 2.

\section{Elemen tos da infraes trutura}

1) Implemen tar estratégia de recursos humanos, a fim de disseminar Educação Ambi ental, permiti ndo estimu lar os funcio nários a atitudes socioambientais e inclusive a tomar-se multiplicadores.

2) Inserir na gestão da qualidade da empresa a gestão ambiental e como consequência implementar a ISO 14000 nos process os organizacionais.

3) Estabelecer no plano estrat égico da empresa a estreita relação entre (PPCP) enxut o e a (P+L), com o objetiv o de implementar a nova con cepção de (PPCPEA) no si stema de produção; para isso, além de planejar um fluxo Just in time, estabelecer o (MRP), a fim de descartar os resíduos de maneira correta, ou até mesmo assimilar o subproduto no fluxo produtivo, a fim de adquirir vantagens ambientais e econômicas.

4) Disseminar consci entização ambiental na empresa, a fim de en volver a estrutura, visando à aceit ação da evolução paradigmática do sistema produtivo para uma manufatura limpa.

Quadro 2 - Elementos da infraestrutura.

Fonte: Oliveira Neto et al. (2010). 
Dessa forma, considera-se de suma importância educar os funcionários operacionais sob a ótica ambiental de maneira transversal, para desenvolver infraestrutura apropriada e incentivar a criação de projetos ecoeficientes intrínsecos ao planejamento e controle da produção.

Fundamentado na Carta de Belgrado, os funcionários das organizações precisam se ater aos objetivos da Educação Ambiental, visando disseminar: conscientização e sensibilidade sobre os problemas ambientais; conhecimento sobre o meio ambiente em relação à influência do homem; atitudes e valores para participação; habilidades para participação ativa; capacidade crítica de avaliação e participação responsável e de urgência em relação às questões ambientais (BARBIERI \& SILVA, 2011). O objetivo central da Educação Ambiental é motivar o envolvimento e ação do ser humano na resolução de problemas ambientais (INTERGOVERNAMENTAL CONFERENCE ON ENVIRONMENTAL EDUCATION, 1977). A concepção da Educação Ambiental deve ser abordada entre os profissionais cujas atividades e decisões geram repercussões significativas sobre o meio ambiente, como administradores, engenheiros, economistas, desenvolvedores de produtos, formuladores de política pública, entre outros (BARBIERI E SILVA, 2011), e pode ser estendida aos stakeholders, visando à transformação para a consciência ambiental de todos os envolvidos (PEARSON, 2011).

Portanto, é importante educar os funcionários sob a ótica ambiental para identificar de maneira completa e clara os responsáveis pelos assuntos socioambientais na empresa (FURTADO, 2005; YUKSEL, 2007), com objetivo de formação de ecotimes, para o desenvolvimento de projetos sustentáveis, alinhamento e monitoramento para geração de ideias entre os envolvidos nesses projetos (NEVENS et al., 2008). Além de disseminar informações sobre os aspectos ambientais e sociais nos fluxos e processos gerais da empresa (NIELSEN \& MULLER, 2009). Para a integração funcional de conhecimento sobre a sustentabilidade, com consciência ambiental, tecnologias limpas, conhecimento tecnológicos e implementação das práticas no sistema produtivo, flexível e adaptativo (SHIN et al., 2008).

É preciso que se harmonize o discurso da Educação Ambiental, destacando a oportunidade de capacitar pessoas a se concentrar na resolução de problemas socioambientais (STRIFE, 2010). O conhecimento e a complexidade dos componentes de materiais e suas interligações para facilitar o entendimento do impacto ambiental e poderão desenvolver produtos que restrinja tais materiais (NIELSEN \& MULLER, 2009). A Educação Ambiental não visa apenas inspirar cidadania responsável, mas principalmente capacitar pessoas para proteger a sociedade de hoje e as condições de sobrevivência futura (STRIFE, 2010). Por meio de situações de aprendizagens, em que os envolvidos têm a oportunidade de explorar, analisar e interpretar as ações humanas em situações de vida real (KYBURZGRABER, 2006).

Conforme Oliveira Neto et al. (2009), a metodologia para Educação Ambiental visa: disseminar princípios de sustentabilidade para a formação de disseminadores do conhecimento, com o propósito de capacitar os envolvidos, além de delegar poder com clareza para responsabilizar a equipe para o gerenciamento dos processos, que incluem planejamento, alocação de recursos e mensuração de desempenho para incentivar a ações práticas.

Segundo Oliveira Neto et al. (2009), a metodologia para Educação Ambiental deve ser disseminada em sete fases: 1) Apresentar, informar e sensibilizar os envolvidos; 2) Priorizar a realidade e necessidades mais urgentes da empresa e de seu ambiente mais próximo; 3) Motivar os envolvidos; 4) Reflexão sobre a educação ambiental, a fim de eliminar a reatividade; 5) Diagnosticar os problemas; 6) Agir, a fim de priorizar os problemas mais urgentes e passíveis de encaminhamentos; 7) Acompanhar e avaliar a implementação para melhorias contínuas. Sendo assim, requer participação, diagnóstico, reflexão e ação dos envolvidos para desenvolver estudos nos processos para germinar análises críticas.

Após desenvolver infraestrutura apropriada, com 
capacitação de funcionários em educação ambiental, criação de departamento para gestão ambiental e considerar a $\mathrm{P}+\mathrm{L}$ no sistema produtivo, é possível estabelecer a estrutura de PPCPEA. Segundo Azzolini
(2004), a estruturação da produção frente a uma nova estratégia competitiva depende das decisões relacionadas ao projeto do sistema de produção. Os elementos da estrutura são apresentados no Quadro 3.

\begin{tabular}{|c|c|}
\hline Elementos da es trutura & Conceituação \\
\hline $\begin{array}{l}\text { 1) Objet ivo de de sempenho } \\
\text { com Pro dução Mais Limpa. }\end{array}$ & $\begin{array}{l}\text { Nova forma de organizar o trabalho e rede de su primentos, a fim de reduzir o uso de recursos e } \\
\text { diminuir a poluição, permiti ndo conquistar vantagem econômica e ambiental. }\end{array}$ \\
\hline $\begin{array}{l}\text { 2)Projetar as instalações } \\
\text { industriais. }\end{array}$ & $\begin{array}{l}\text { Arranj o físico fabri l com máquinas e equipamen tos com tecnologias limpas e redes de operações e } \\
\text { localização geográfica estra tégica, a fim de evitar desperdício de tempo e combustível para reduzir } \\
\text { o nível de } \mathrm{CO}^{2} \text { na atmos fera. }\end{array}$ \\
\hline 3)Cap acidade produtiva. & $\begin{array}{l}\text { A organização precisa crescer economicamente, mas com Educação Ambiental, visando à } \\
\text { sustentabilidade. }\end{array}$ \\
\hline $\begin{array}{l}\text { 4) Estratégia de proces } .0 \\
\text { ambiental. }\end{array}$ & Vi sa considerar na estrat égia em operações a (P+L) como rotina do (PPCPEA). \\
\hline 5) Tecnologia limpa. & $\begin{array}{l}\text { Controles automatizados do processo por meio de tecnologia limpa, que permitem reduzir o } \\
\text { descarte de efluentes ou outros resíduos, bem como o u so de matéria prima e energia. }\end{array}$ \\
\hline $\begin{array}{l}\text { 6)Terceirização e } \\
\text { verticalização. }\end{array}$ & $\begin{array}{l}\text { O proce sso de homol ogação de forn ecedores certificados pela ISO 14001, visando transformar o } \\
\text { caráter linear do sistema industrial em um si stema cíclico, no qual matérias-primas, energia e } \\
\text { resíduos sejam sempre reutilizados. }\end{array}$ \\
\hline $\begin{array}{l}\text { 7) Planejamento e } \\
\text { de senvolvimento de } \\
\text { produtos ambientalmente } \\
\text { corretos. }\end{array}$ & $\begin{array}{l}\text { Estab elecer engenharia simultânea, com a presença de um engenh eiro ambiental, a fim de avaliar } \\
\text { todos os produtos, componentes ou matérias-primas utilizad os, a fim de selecionar categorias de } \\
\text { produtos para identificar o de menor impacto ambiental; além disso, é necessário considerar } \\
\text { aspectos de ecodesign, a fim de identificar e cotar produtos recicláveis, que permitam a } \\
\text { reutil ização e a remanufatura. }\end{array}$ \\
\hline
\end{tabular}

Quadro 3 - Elementos da estrutura.

Fonte: Oliveira Neto et al. (2010).

\section{Método de Pesquisa}

Para a coleta de dados utilizou-se o método de estudo de caso por meio da observação e participação, a partir da coleta de dados de natureza qualitativa com análise quantitativa. Segundo Eisenhardt (1989), o estudo de caso é uma estratégia de pesquisa focada em compreender a dinâmica existente em cada cenário. Estudos de caso normalmente combinam métodos de coleta de dados, como arquivos, entrevistas, questionários e observações. As evidências podem ser qualitativas, quantitativas ou ambas. Segundo Bogdan e Biklen (1992), a observação participante e a entrevista semiestruturada são os instrumentos mais comuns da pesquisa qualitativa e que melhor representam suas características. Por meio desta, é possível compreender "a importância da linguagem e das histórias na vida de uma pessoa como meio para seu conhecimento e sua compreensão" (SEIDMAN, 1991).
Sobre a pesquisa quantitativa, permite-se a mensuração de opiniões, reações, hábitos e atitudes em um universo, por meio de uma amostra que o represente estatisticamente (DENZIN; LINCOLN, 2005; NEVES, 1996; HAYATI; KARAMI; SLEE, 2006). Para a análise quantitativa foi utilizado o método desenvolvido pelo Instituto Wuppertal, que pode avaliar as mudanças ambientais associadas à extração de recursos de seus ecossistemas naturais. Dessa forma, para suprir com um fluxo de materiais um sistema, uma quantidade maior de material foi previamente processada em vários compartimentos ambientais. Os compartimentos são classificados em: abiótico, biótico, água e ar. Segundo Odum (1998), o compartimento biótico consiste no conjunto de todos os organismos vivos, como plantas e decompositores; o compartimento abiótico é o conjunto de fatores não vivos de um ecossistema, mas que influenciam no meio biótico, e consiste na temperatura, pressão, pluviosidade 
de relevo, entre outros. Aquantidade total de material de cada compartimento que foi processado para suprir um dado materialé denominada Intensidade de Material. Para determinar a Intensidade de Material, o fluxo de entrada de massa (expresso nas unidades correspondentes) é multiplicado pelo fator MIF (mass intensity factors), que corresponde à quantidade de matéria necessária para produzir uma unidade de fluxo de entrada. Os valores de MIF usados no presente trabalho estão na Tabela 1.

Tabela 1 - Fatores de Intensidade de Material usados no presente trabalho.

\begin{tabular}{c|c|c|c|c} 
& Material abiótico & Material biótico & Água & Ar \\
\hline${\text { Água potável }(\mathrm{L})^{\mathrm{a}}}^{\mathrm{a}}$ & 0,01 & & 1,3 & 0,001 \\
\hline $\begin{array}{c}\text { Energia elétrica } \\
\text { industrial }(\mathrm{kWh})^{\mathrm{b}}\end{array}$ & 2,67 & & 37,9 & 0,640
\end{tabular}

Fonte: Dados dos autores.

\section{Estudo de Caso}

Nesta seção será apresentado o estudo de caso desenvolvido por meio de entrevista e observação participante em cinco fases: (i) buscou-se, de maneira qualitativa, mostrar os fatores determinantes que impulsionaram a empresa à criação do projeto, considerando a sensibilização dos funcionários em Educação Ambiental imprescindível para a formação de ecotime, que permitiu posteriormente, sob a liderança do PCP, estabelecer mudanças incrementais na infraestrutura e estrutura da produção; (ii) acrescentouse o método quantitativo, a fim de estabelecer análise e avaliação do cenário produtivo, permitindo estabelecer diagnóstico e balanço material; (iii) será apresentado a implementação e resultados do projeto de estruturação da manufatura no sistema produtivo; (iv) medidas de desempenho e (v) plano de continuidade.

\section{Fatores determinantes que impulsionaram a} criação do projeto

O objetivo principal é evidenciar a implementação do (PPCPEA) em um estudo de caso caracterizado por uma Indústria multinacional de Transformação do ramo químico de produtos de limpeza, no qual considera a necessidade de educar os funcionários, o diretor de supply chain e os planejadores da produção de maneira transversal sob a ótica ambiental. No Quadro 4 mencionam-se os fatores determinantes que norteiam a concepção paradigmática do sistema produtivo da empresa pesquisada. 


\begin{tabular}{|l|l|}
\hline \multicolumn{1}{|c|}{$\begin{array}{c}\text { Fatores } \\
\text { determinantes }\end{array}$} & \multicolumn{1}{c|}{ PEGEM da empresa em estudo } \\
\hline Direcionadores & $\begin{array}{l}\text { Imagem socioambiental (Marketing verde e ISO 14000) visando à competitividade. } \\
\text { Segundo Contador (2008), algumas empresas estão buscando manter a imagem de empresa confiável, visando à } \\
\text { transparência e maior competitividade. }\end{array}$ \\
\hline $\begin{array}{l}\text { Objetivos de } \\
\text { desempenho }\end{array}$ & Produção Mais Limpa. \\
\hline Capacitadores & $\begin{array}{l}\text { Centro Nacional de Tecnologias Limpas - CNTL/ Indicador econômico/ Indicador ambiental - Wuppertal/ Ênfase na } \\
\text { metodologia de RH e Capacitador voltado a projetos sustentáveis }\end{array}$ \\
\hline $\begin{array}{l}\text { Práticas e } \\
\text { princípios }\end{array}$ & $\begin{array}{l}\text { a) Infraestrutura para o controle das operaçães } \\
\text { Desenvolver pessoas com educação ambiental; Conquistar certificação ISO 14000: 2004; } \\
\text { - Planejamento do sistema produtivo "Lean and Green"; } \\
\text { b) Estruturação da estratégia de processo no sistema produtivo } \\
\text { - Objetivo de desempenho - Produção Mais Limpa; } \\
\text { - Pequenas melhorias no layout; } \\
\text { - Reduzir desperdício de água e tempo no processo de limpeza melhorando a capacidade de produção; } \\
\text { - Implementação de tecnologia limpa para reduzir consumo de energia elétrica; } \\
\text { - Homologação de fornecedores, considerando a sustentabilidade como critério ganhador de pedidos; } \\
\text { - Desenvolvimento de produtos ecologicamente corretos. }\end{array}$ \\
\hline
\end{tabular}

Quadro 4 - Fatores determinantes da concepção paradigmática no sistema produtivo da empresa pesquisada.

Fonte: Dados dos autores.

Sensibilização e disseminação da educação ambiental de maneira transversal e formação do ecotime

A Educação Ambiental foi disseminada para os funcionários do setor de produção da empresa química pesquisada, visando à conscientização sobre práticas de sustentabilidade no sistema produtivo. A organização considerou de suma importância capacitar o diretor de supply chain, os dois gestores de planejamento e controle da produção e os 180 funcionários operacionais, sendo 90 do turno do dia e 90 do turno da noite.

Para isso a empresa decidiu contratar dois professores/consultores do Serviço Nacional de Atividade Industrial-SENAI para gerenciar o processo e capacitar os envolvidos. É importante salientar que foi aplicada a metodologia para Educação Ambiental fundamentada em Oliveira Neto et al. (2009). O direcionamento estratégico, que formou o escopo do projeto exigido pela empresa química, consiste em: (i) Princípios, a formação de disseminadores sobre práticas ambientais no sistema produtivo; (ii) Propósito, o treinamento e capacitação; (iii) Poder para sensibilização dos envolvidos para delegar e responsabilizá-los; e (iv) Processos e prática, a fim ensinar na teoria e na prática analisar os processos da manufatura por meio da ferramenta de produção mais limpa e metodologia wuppertall para avaliar a redução do impacto ambiental resultantes das ações realizadas.

Para atender à necessidade da empresa química, os professores/consultores organizaram a sistemática das aulas, considerando segundas e quartas. Por turno ministravam-se dois períodos: pela manhã, das $8 \mathrm{~h}$ às $12 \mathrm{~h}$, para 45 operários, e à tarde, das $13 \mathrm{~h}$ às $17 \mathrm{~h}$, mais 45 operários, o diretor de supply chain e os dois planejadores. No segundo turno, uma turma com 45 operários das $18 \mathrm{~h}$ às $22 \mathrm{~h}$ e outro com mais 45 operários das $23 \mathrm{~h}$ às $3 \mathrm{~h}$. Também foi desenvolvido um cronograma das ações a serem seguidas em relação ao tempo. Na Figura 2 mostram-se no vértice y as sete atividades e, no eixo x, o período em meses para cada atividade, sumarizando oito meses. 
7 - Medidas de desempenho para melhorias contínuas.

6 - Desenvolvimento de planos de ação com priorização.

5 - Formação de ecotimes para diagnosticar os problemas.

4 - Reflexão sobre educação ambiental.

3 - Motivar os envolvidos.

2 - Estabelecer prioridades/ escopo.

1 - Apresentar, sensibilizar o pessoal.

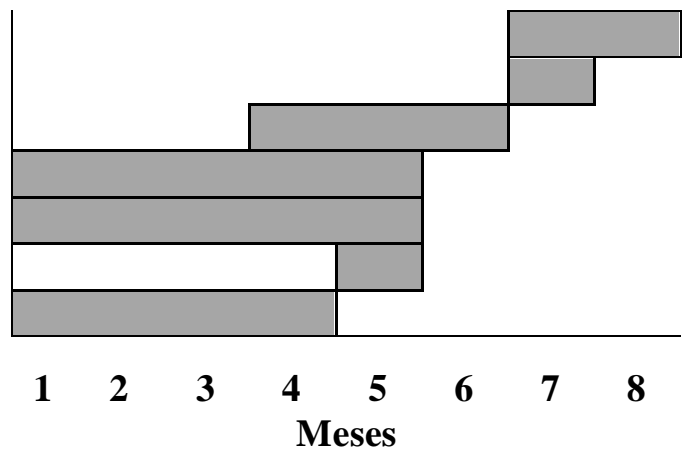

Figura 2 - Cronograma para implementação de educação ambiental no sistema produtivo.

Fonte: Dados dos autores.

No Quadro 5 apresenta-se o conteúdo programático (SENAI, 2003) ministrado nos primeiros quatro meses, visando sensibilizar o pessoal à Educação Ambiental sobre práticas de produção mais limpa, com carga horária de 64 horas. $\mathrm{O}$ tema Educação Ambiental foi discutido de maneira transversal em todos os dias de aprendizagem aos colaboradores e gestores "cujas atividades e decisões geram repercussões significativas sobre o meio ambiente" (BARBIERI \& SILVA, 2011), visando motivar o envolvimento e ação do ser humano na resolução de problemas ambientais (INTERGOVERNMENTAL CONFERENCE ON ENVIRONMENTAL EDUCATION, 1977).

1. Evolução das questões ambientais e mudança incremental no sis tema produtivo

$1.1 \mathrm{O}$ que é produção mais limpa

1.2 Produção mais li mpa X Fim-de-tubo

2. Benefícios da Produção Mais Limpa

2.1 Benefícios Ambientais - eli minação/ redução de resíduos; produção sem polui ção; eficiên cia energética; saúde e segurança no trabal ho; pro dut os a mbientalm ente adequados e embalagens ambientalmente adequadas.

2.2 Benefícios econômicos

3. Implementação da Produção Mais Limpa

3.1 Etapa 1 - Formação do ecotime

3.2 Etapa 2 - Estudo do fluxograma do processo; realização do diagnóstico ambiental e de processo e seleção do foco de aval iação.

3.3 Etapa 3 - Elaboração do bal anço mat erial e estabelecimen to de indicadores; identificação das causas da geração de resíduos e identificação de opções de produção mais limpa

3.4 Etapa 4-Avali ação técni ca, ambiental e econômica e seleção de oportunidad es viávei s

3.5 Etapa 5 - Plano de implementação e monitoramento e plano de conti nuidade.

Quadro 5 - Conteúdo programático das aulas.

Fonte: Centro Nacional de Tecnologias Limpas (SENAI, 2003). 
No quarto mês avaliou-se a aplicação dos alunos no curso e selecionaram-se os funcionários com melhor desempenho para compor o ecotime, que se tornaram responsáveis em diagnosticar os problemas ambientais no sistema produtivo, desenvolver projetos sustentáveis e estabelecer alinhamento e monitoramento para geração de ideias entre os envolvidos nesses projetos. A meta estabelecida foi de $85 \%$, sendo $30 \%$ da nota de participação e $70 \%$ por meio de teste com 20 questões. A Figura 3 mostra que apenas 33 funcionários atingiram a meta, sendo 17 funcionários do turno dia, entre estes o diretor de supply chain e outro o planejador da produção, e 16 funcionários da noite, considerando um planejador da produção.

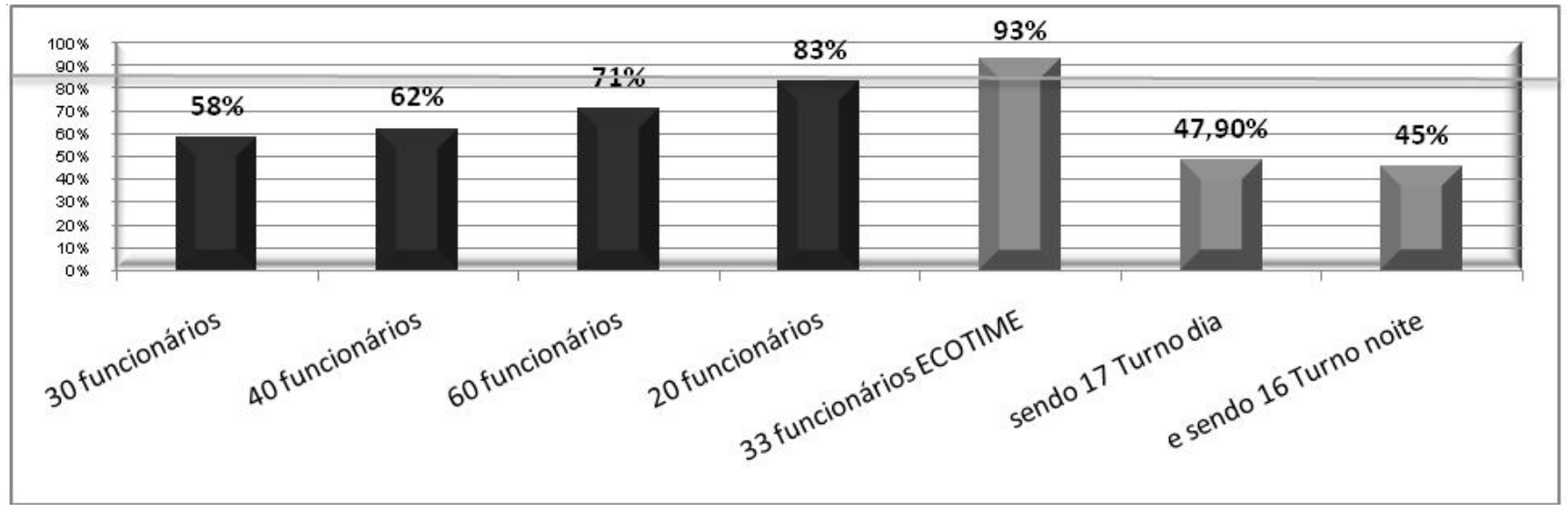

Figura 3 - Primeira avaliação de desempenho dos funcionários na aprendizagem sobre educação ambiental. Fonte: Dados dos autores.

Entre o quarto, quinto e sexto meses de trabalho, foi desenvolvido pelo ecotime o plano de ação com dez prioridades "PCPEA" (Quadro 6). É importante salientar que os dois planejadores de produção foram os principais agentes do ecotime para desenvolver o detalhamento do plano de ação, devido à visão holística do processo. Segundo os planejadores, no momento da sensibilização e disseminação, eles já refletiram nos pontos de melhorias ambientais no sistema produtivo, por conhecerem o processo. Dessa forma, considerase a temática do modelo "PCP com Educação Ambiental" como inovação na literatura, aplicado após a publicação do modelo em 2010. Também é importante ressaltar que a $\mathrm{P}+\mathrm{L}$ está intrínseca em todo o processo, como consta do modelo, mas que a implementação da $\mathrm{P}+\mathrm{L}$ só foi possível após a sensibilização e disseminação da Educação Ambiental de maneira transversal entre os envolvidos.

\begin{tabular}{|l|l|}
\hline Priorização & \multicolumn{1}{c|}{ Atividades } \\
\hline 1 & Retransmitir os conceitos de produção mais limpa e educação ambiental para150 reprovados e entrantes. \\
\hline 2 & Constatações das necessidades de infraestrutura para o projeto com apoio da alta administração. \\
\hline 3 & $\begin{array}{l}\text { Constatações dos aspectos necessários para estruturação do projeto no que tange a estratégia de processo das etapas de } \\
\text { implementação da produção mais limpa. }\end{array}$ \\
\hline 4 & Análise do cenário produtivo para implementação do projeto Minimization (Sequenciamento de Cargas). \\
\hline 5 & $\begin{array}{l}\text { Desenvolver análises no sistema produtivo e planejamento e controle da produção a fim de desenvolver diagnóstico } \\
\text { ambiental. }\end{array}$ \\
\hline 6 & Elaboração do balanço de material para identificação das causas da geração de resíduos. \\
\hline 7 & Implementação do projeto de estruturação do sistema produtivo Minimization (Sequenciamento de Cargas. \\
\hline 8 & Resultados - Avaliação das vantagens econômicas e ambientais. \\
\hline 9 & Medidas de desempenho para melhorias contínuas. \\
\hline 10 & Estender os conceitos de produção mais limpa e educação ambiental para a rede de suprimentos. \\
\hline
\end{tabular}

Quadro 6 - Plano de ação com dez prioridades "PCPEA".

Fonte: Dados dos autores. 
Sendo assim, o primeiro desafio para o ecotime será disseminar o conteúdo para os funcionários reprovados e os entrantes. Depois serão analisadas as constatações de necessidades de infraestrutura e estrutura para o desenvolvimento do projeto; em seguida, visa-se estabelecer análise no sistema produtivo, com o objetivo de elaborar o balanço material para identificar as causas da geração de resíduos antes da implementação do projeto. Também serão avaliados os resultados no que tange às vantagens econômicas e ambientais e, por fim, pretende-se inserir medidas de desempenho, visando a melhorias contínuas, além de estender a Educação Ambiental para todos os funcionários da rede de suprimentos, incluindo fornecedores e clientes nos próximos anos. Na Figura 4 mostram-se melhorias nos resultados em relação aos conceitos de Educação Ambiental e produção mais limpa quando foram retransmitidos pelo pessoal do ecotime, em que $80 \%$ tiraram nota acima de 85 . Segundo o entrevistado, a melhoria nos resultados ocorreu por motivo de alinhamento na linguagem.

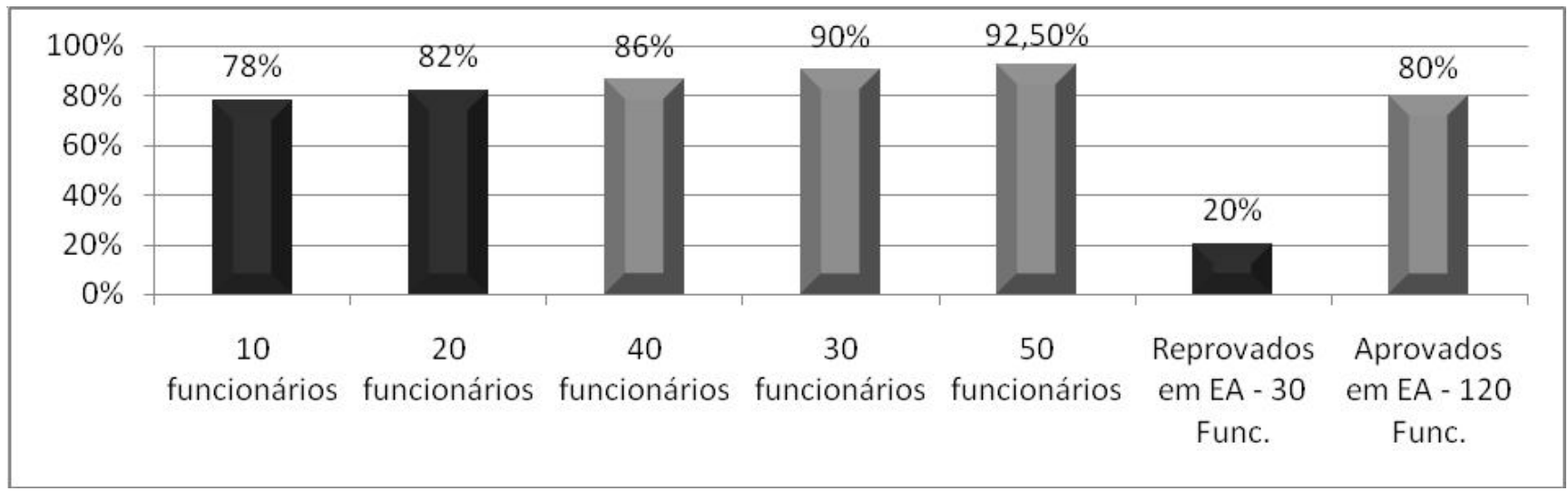

Figura 4 - Segunda avaliação de desempenho dos funcionários na aprendizagem sobre Educação Ambiental.

Fonte: Dados dos autores.

Após conquistar mais adeptos, desenvolveu-se a formalização junto à alta administração das necessidades de infraestrutura para a implementação da produção mais limpa no sistema produtivo, assunto que será tratado na próxima seção.

Infraestrutura para o controle das operações

Os aspectos de infraestrutura (Quadro 7) foram desenvolvidos com base na sensibilização e disseminação da Educação Ambiental para flexibilizar as pessoas para o processo de mudança, para: desenvolver pessoas com Educação Ambiental, a implementação da gestão ambiental com certificação ISO 14001 e o planejamento do setor produtivo frente ao PEGEM - Manufatura Limpa. 


\begin{tabular}{|c|c|}
\hline Aspectos de infraestrutura & Constatações da observação participante \\
\hline $\begin{array}{l}\text { Desenvolver pessoas com } \\
\text { educação ambiental. } \\
\text { - Assunto discutido de } \\
\text { maneira transversal na } \\
\text { sensibilização e } \\
\text { disseminação }(3.2 .1) \text { e na } \\
\text { estruturação da } \mathrm{P}+\mathrm{L}(3.4 .1) \text {. }\end{array}$ & $\begin{array}{l}\text { Capacitação do ecotime por meio de abordagem colaborativa, não somente treinar o pessoal de } \\
\text { produção para atingir as metas de produção (produção dia, setup, capacidade ociosa, } \\
\text { capacidade protetora) e treiná-los para }(\mathrm{P}+\mathrm{L}) \text {. Para isso estruturou a liderança e poder para o } \\
\text { controle do processo, depois diagnosticou a cultura organizacional a fim de educá-los sobre } \\
\text { educação ambiental, e buscou-se também formar multiplicadores para a disseminação do } \\
\text { conhecimento. }\end{array}$ \\
\hline $\begin{array}{l}\text { Implementação da gestão } \\
\text { ambiental com } \\
\text { certificação pela ISO } \\
\text { 14000:2004. } \\
\text { - A alta administração } \\
\text { definiu a política ambiental. }\end{array}$ & $\begin{array}{l}\text { a) seja apropriada à natureza, escala e impactos ambientais de suas atividades, produtos e } \\
\text { serviços; b) incluindo um comprometimento com a melhoria contínua e com a prevenção de } \\
\text { poluição; c) incluindo um comprometimento em atender aos requisitos legais aplicáveis e } \\
\text { outros requisitos subscritos pela organização que se relacionem a seus aspectos ambientais; d) } \\
\text { fornecer uma estrutura para o estabelecimento e análise crítica dos objetivos e metas } \\
\text { ambientais; e) sendo documentada, implementada e mantida; f) sendo comunicada a todos que } \\
\text { trabalhem na organização ou que atuem em seu nome; g) estando disponível para o público. A } \\
\text { empresa química estabeleceu um cronograma para o cumprimento das atividades durante um } \\
\text { ano até conquistar a certificação ISO 14001:2004, as atividades incluem os aspectos de } \\
\text { infraestrutura e estruturais. }\end{array}$ \\
\hline $\begin{array}{l}\text { Planejamento do setor } \\
\text { produtivo frente ao atual } \\
\text { PEGEM - Manufatura } \\
\text { Limpa. } \\
\text { - Redução da poluição e ser } \\
\text { ecoeficiente; } \\
\text { - Mercado socioambiental } \\
\end{array}$ & $\begin{array}{l}\text { Implementação do MRP ambiental a fim de gerar relatórios que estabeleçam a quantidade de } \\
\text { resíduos esperada durante o processo de produção e quando ocorrerá para a destinação correta. } \\
\text { "PPCP Lean and Green", que permitiu rever os processos a fim de reduzir os tempos, os } \\
\text { custos, racionalizar o uso de matéria prima por meio da reciclagem ou da reutilizaçãa. Outra } \\
\text { característica importante, é planejar produtos ambientais e analisar o ciclo de vida, também } \\
\text { buscando otimizar e adequar o transporte a fim de reduzir a emissão de } \mathrm{CO}^{2} \text { e outros gases } \\
\text { venosos ao ecossistema (US EPA, 2000). }\end{array}$ \\
\hline
\end{tabular}

Quadro 7 - Constatações das necessidades de infraestrutura para o projeto com apoio da alta administração.

Fonte: Dados dos autores.

\section{Projeto de estruturação do sistema produtivo}

Neste tópico é apresentado o projeto de estruturação do sistema produtivo na empresa química (Quadro 8), que considera a Educação Ambiental de maneira transversal no cerne do PCP, com o objetivo de estabelecer as etapas de implementação da estratégia de processo da produção mais limpa, que visa: a) estudar o fluxograma do processo produtivo; b) elaborar balanço material; c) identificar opções de $(\mathrm{P}+\mathrm{L})$; d) estabelecer avaliação técnica econômica e ambiental; e) implementar o plano e monitoramento; e f) desenvolver plano de continuidade. 


\begin{tabular}{|c|c|}
\hline $\begin{array}{l}\text { Aspectos para estruturação } \\
\text { do projeto }\end{array}$ & Constatações da observação participante \\
\hline $\begin{array}{l}\text { 4.1 Desenvolver análises no } \\
\text { sistema produtivo e } \\
\text { planejamento e controle da } \\
\text { produção a fim de } \\
\text { desenvolver diagnóstico } \\
\text { ambiental. }\end{array}$ & $\begin{array}{l}\text { Desenvolver estudo no processo produtivo com o apoio do ecotime a fim de levantar o } \\
\text { quantitativo de matéria-prima, água e energia, permitindo avaliar a geração de resíduos } \\
\text { durante e após o processamento com o objetivo da formação de uma estratégia de } \\
\text { minimização da geração de resíduos, efluentes e emissões, elucidando parâmetros } \\
\text { econômicos e ambientais existentes no sistema produtivo. Para a avaliação é preciso } \\
\text { conhecer regulamentos legais, a toxicidade dos resíduos, e os custos envolvidos. }\end{array}$ \\
\hline $\begin{array}{l}\text { 4.2 Elaboração do balanço } \\
\text { de material para } \\
\text { identificação das causas da } \\
\text { geração de resíduos. }\end{array}$ & $\begin{array}{l}\text { 1) Matérias-Primas - uso de matérias-primas com possibilidade de reutilização, reciclagem e } \\
\text { remanufatura comparada as compras tradicionais; } \\
\text { 2) Causas relacionadas aos resíduos - inexistência de separação de resíduos, } \\
\text { desconsideração pelo potencial de reutilização de determinados resíduos, não há recuperação } \\
\text { de energia nos resíduos dos produtos e emissões e manuseio inadequado; } \\
\text { 3) Know how/processo - má utilização dos parâmetros de processo e uso de tecnologias de } \\
\text { processo ultrapassadas. }\end{array}$ \\
\hline $\begin{array}{l}\text { 4.3 Implementação do } \\
\text { projeto na estrutura do } \\
\text { sistema produtivo } \\
\text { Minimization } \\
\text { (Sequenciamento de } \\
\text { Cargas). }\end{array}$ & $\begin{array}{l}\text { Identificação das opções de Produção Mais Limpa: 1) Modificação do processo envolve } \\
\text { estratégias de modificação no sistema de produção; 2) As boas práticas operacionais - } \\
\text { adoção de medidas de procedimento, técnicas para minimizar os resíduos, efluentes e } \\
\text { emissões; 3) Substituição de matérias-primas e materiais auxiliares e 4) Reciclagem Interna } \\
\text { estão relacionadas a todos os processos de recuperação de matérias-primas e materiais } \\
\text { auxiliares. }\end{array}$ \\
\hline $\begin{array}{l}5 \text { Resultados - Avaliação das } \\
\text { vantagens econômicas e } \\
\text { ambientais. }\end{array}$ & $\begin{array}{l}\text { Avaliação técnica, econômica e ambiental: 1) Na avaliação técnica o impacto da medida } \\
\text { proposta sobre o processo, produtividade, segurança, etc., 2) Na avaliação ambiental a } \\
\text { quantidade de resíduos, efluentes e emissões que será reduzida; 3) Na avaliação econômica } \\
\text { os investimentos necessários e as possíveis vantagens. }\end{array}$ \\
\hline $\begin{array}{l}\text { 5.3 Medidas de desempenho } \\
\text { para melhorias contínuas. }\end{array}$ & $\begin{array}{l}\text { Plano de implementação e monitoramento: 1) Implementação das especificações técnicas } \\
\text { detalhadas e 2) Monitoramento das medidas a serem implantadas. }\end{array}$ \\
\hline $\begin{array}{l}5.4 \text { Estender os conceitos de } \\
\text { produção mais limpa e } \\
\text { educação ambiental para a }\end{array}$ & $\begin{array}{l}\text { Plano de continuidade: Após o Programa de Produção mais Limpa no processo ser } \\
\text { considerado como implementado é importante não somente avaliar os resultados obtidos, } \\
\text { mas, sobretudo, criar condições para que o programa tenha sua continuidade assegurada }\end{array}$ \\
\hline
\end{tabular}

Quadro 8 - Constatações dos aspectos necessários para estruturação do projeto.

Fonte: Dados dos autores.

Fundamentado nas constatações das necessidades de infraestrutura para o projeto, os dois planejadores da produção, sensibilizados à Educação Ambiental, estabeleceram os aspectos necessários para a estruturação do projeto, que originou o planejamento das etapas de implementação da estratégia de processo da produção mais limpa. Na próxima seção apresentarse-á o projeto de $(\mathrm{P}+\mathrm{L})$ "Lean and Green" para minimização de resíduos e melhorias no sequenciamento de cargas desenvolvido pelo ecotime e, principalmente, pelos planejadores da produção com Educação Ambiental em três fases: (i) no início do projeto os planejadores da produção com Educação Ambiental estabeleceram análises no sistema produtivo e nas atividades do planejamento e controle da produção, a fim de desenvolver diagnóstico ambiental; (ii) elaboraram o balanço material para identificação das causas da geração de resíduos; e (iii) implementaram o projeto de estruturação no sistema produtivo Minimization (Sequenciamento de Cargas).

\section{Análise do cenário produtivo para implementação do projeto Minimization (Sequenciamento de Cargas)}

$\mathrm{O}$ ecotime considera de suma importância a implementação da P+L no cerne das ações de PCP e para isso pediu apoio ao centro técnico e a qualidade assegurada visando aumentar a produtividade por equipamentos de produção; reduzir os tempos gastos para a produção de cada batelada de produto e reduzir os impactos ambientais gerados durante o processo produtivo. Foi de suma relevância capacitar os 
planejadores da produção em educação ambiental, que nomearam o setor como Planejamento e Controle da Produção com Educação Ambiental.

\section{Desenvolver análises no sistema produtivo e PCP para diagnóstico}

Para cada batelada de produção o consumo de tempo por dia varia de 1 a 5 horas, envolvendo as seguintes etapas, conforme mostra a Figura 5: 1) Separação - separação das matérias-primas (MP) com ordem de trabalho (OT) impressa; 2) Adição de matérias primas - suprimento de matéria-prima na parte superior do tanque; 3) Processo de agitação - processo de homogeneização das matérias-primas; 4) Análise da qualidade do produto acabado - o departamento de qualidade assegurada testa a qualidade do produto quanto a suas especificações de uso e autoriza a transferência do produto acabado para o processo de preenchimento das embalagens, no caso de produto não autorizado deve-se recuperar o produto final até que atenda às especificações quanto ao uso; 5) Envase - subprocesso agrupamento dos frascos e embalagens; e 6) Limpeza - consiste em enxaguar o tanque de produção com objetivo de remover o resíduo do produto fabricado, impregnado nas paredes do tanque. A água na forma de resíduo circula através do tanque, bombas e tubulações por onde o produto havia circulado e, ao final, destina-se para a estação de tratamento de efluentes. O processo era realizado até que se removesse completamente o resíduo, de forma que não ocorra contaminação cruzada do produto posterior por corantes, perfumes, tenso-ativos e/ou matérias-primas incompatíveis. Após o processo de limpeza, o equipamento de produção fica disponível para nova batelada.

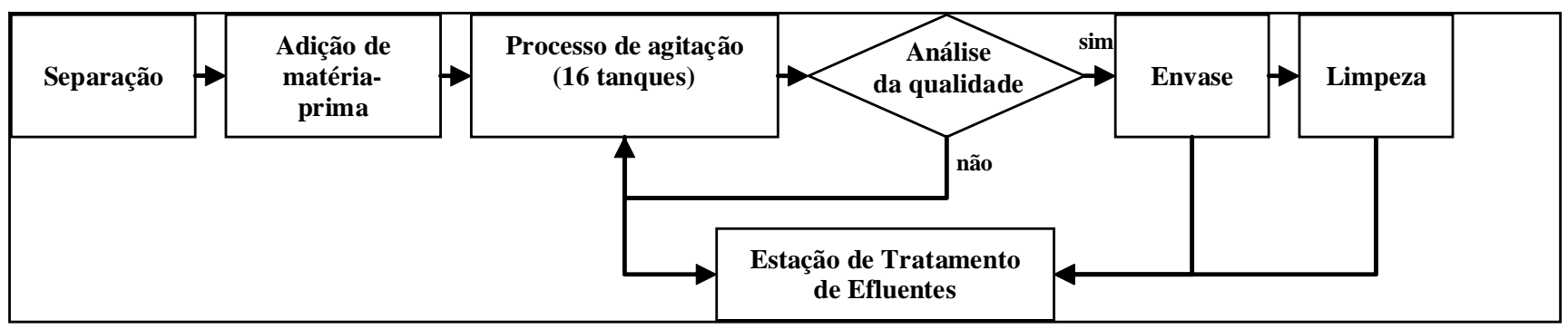

Figura 5 - Processo de fabricação de produtos químicos à limpeza.

Fonte: Dados dos autores.

O tempo médio gasto no processo de limpeza era de 20 minutos, e havia também um consumo considerável de tempo nas etapas do próprio processo produtivo em cada equipamento de produção. Produzia-se, em média, até cinco bateladas por dia. Isso implicava um gasto médio de até 1 hora e 40 minutos por dia, apenas com o processo de limpeza.

Como não se conheciam os tempos gastos em cada etapa do processo, não havia planejamento sobre o que cada equipamento poderia produzir em um determinado dia, ocasionando, às vezes, a ociosidade do equipamento. Comisso, o equipamento permanecia à disposição, mas não havia bateladas programadas para ele para o restante do dia.

\section{Elaboração da análise sobre o balanço de} material para identificação das causas da geração de resíduos para a implementação da produção mais limpa

A empresa consome mensalmente $3.197 \mathrm{~m}^{3}$ de água, sendo $2.333 \mathrm{~m}^{3}$ para a fabricação do produto e $633 \mathrm{~m}^{3}$ para as lavagens de tanques agitadores, tubulações e envase. O Quadro 9 detalha o consumo de água por dia e por mês do subprocesso de limpeza, considerando o tempo de $1 \mathrm{~h} 40$ por dia e $43 \mathrm{~h} 20$ no mês, considerando o mês com 26 dias úteis. 


\begin{tabular}{|c|c|c|}
\hline Etapas da limpeza & Consumo de água por dia & Consumo de água por mês \\
\hline Tubulações & $0,2 \mathrm{~m}^{3}$ por lavagem $\times 5$ bateladas $=\mathbf{1} \mathbf{~ m}^{3}$ por dia & $26 \mathrm{~m}^{3}$ \\
\hline Envase & $0,5 \mathrm{~m}^{3}$ por lavagem $\times 5$ bateladas $=\mathbf{2 , 5} \mathbf{~ m}^{\mathbf{3}}$ por dia & $65 \mathrm{~m}^{3}$ \\
\hline Lavagem dos tanques & 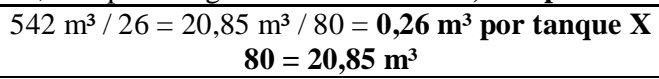 & $542 \mathrm{~m}^{3}$ \\
\hline Totais & $24,35 \mathrm{~m}^{3}$ & $633 \mathrm{~m}^{3}$ \\
\hline
\end{tabular}

Quadro 9 - Consumo de água dia e mês para as lavagens antes da implementação do projeto.

Fonte: Dados dos autores.

O componente água representa $2.333 \mathrm{~m}^{3}$ por mês na fabricação de produtos, por dia $89,73 \mathrm{~m}^{3} \mathrm{em} 8$ horas de trabalho. Outro fator relevante é o consumo de energia: o consumo médio é apresentado no
Quadro 10. A empresa de produtos químicos consome em sua fabricação $5.125,375 \mathrm{kWh}$ ou 184,59 GJ de energia elétrica, com um custo de $\mathrm{R} \$ 1.335,36$.

\begin{tabular}{|c|c|c|c|}
\hline $\begin{array}{c}\text { Consumo médio mensal de Energia } \\
\text { Elétrica para 130 bateladas }\end{array}$ & $\begin{array}{c}\text { Cada Batelada } \\
\text { consome }\end{array}$ & $\begin{array}{c}\text { Custo em R\$ mensal de } \\
\text { Energia Elétrica }\end{array}$ & $\begin{array}{c}\text { Custo em R\$ por Batelada de } \\
\text { Energia Elétrica }\end{array}$ \\
\hline $5125,375 \mathrm{kWh}$ & $39,43 \mathrm{kWh}$ & $\mathrm{R} \$ 1.335,36$ & $\mathrm{R} \$ 10,27$ \\
\hline
\end{tabular}

Quadro 10 - Consumo de energia elétrica mensal e por batelada na fabricação de $2.799,6 \mathrm{~m}^{3}$ de produtos.

Fonte: Dados dos autores.

O custo hora/homem da empresa química é de R\$2 200,52 por hora de produção. As perdas devido à hora improdutiva na limpeza são de aproximadamente $1 \mathrm{~h} 40$ por dia e representa o total de $\mathrm{R} \$ 334,87$ por dia; mensalmente, $\mathrm{R} \$ 8.706,58$.

\section{Implementação e resultados do projeto de estruturação no sistema produtivo}

O projeto foi implantado em todos os equipamentos de produção entre janeiro e maio de 2009 , num total de 16 tanques de produção (agitadores) e na máquina de envase. Dessa forma, primeiro estabeleceram-se mudanças incrementais no sistema produtivo para tornar a manufatura limpa. Para isso, foram implantados: (i) tecnologias limpas no que tange a motores para reduzir $30 \%$ de energia elétrica e equipamentos para controles numéricos e sistemas automáticos de identificação, (ii) mudanças no plano de sequenciamento, e (iii) mudanças no layout da manufatura. Em segundo, foram avaliadas as vantagens econômicas e ambientais da implementação do projeto e elucidados os ganhos lean no que tange à otimização da capacidade produtiva, que resultou em aumento da produção, redução de custos de produção, redução no custo por litro produzido e aumento do lucro.
Em terceiro, foram desenvolvidas medidas de desempenho, visando a melhorias contínuas e, por fim, mostra-se o plano de continuidade que visa estender os conceitos de $\mathrm{P}+\mathrm{L}$ e Educação Ambiental para a rede de suprimentos.

\section{Mudanças incrementais no sistema produtivo para concepção da Manufatura Limpa}

Nos agitadores e no envase foram trocados os motores trifásicos por motores trifásicos com selo PROCEL com inversores de frequência de economia de energia. O selo Procel tem por objetivo indicar os produtos que apresentam os melhores níveis de eficiência energética do mercado, proporcionando assim economia de energia elétrica. Os inversores de frequência são equipamentos de baixo custo para o controle da velocidade de motores de indução trifásicos, o que gera uma economia de energia sem prejudicar a qualidade final do sistema. A grande vantagem de utilização de inversores é que, além de gerar economia de $30 \%$ de energia elétrica, também reduz o custo de instalação do sistema.

Também foram instaladas máquinas de controle numérico e sistemas automáticos de identificação nos 
tanques agitadores e na máquina de envase, a fim de mensurar a quantidade de matéria-prima e energia elétrica gastos no processo produtivo. Essas tecnologias limpas permitiram desenvolver análise crítica sobre possíveis melhorias na produção ecoeficiente, visando reduzir o consumo de energia.

O primeiro passo foi observar o tempo gasto em todas as etapas do processo de cada batelada, conforme relatado anteriormente em média de 1 a 5 por batelada, que corresponde a 6 h20min. de produção e 1h40min. de lavagem. Então se buscou, posteriormente, identificar as possibilidades de melhoria sem que isso viesse a comprometer a qualidade do produto. O projeto objetivou, conforme o Quadro 11, reduzir o tempo ocioso gasto com a limpeza, que passou a ser de 20 minutos por dia e 8 h40 no mês, e o consumo de água na limpeza, que passou a ser de 4,86 $\mathrm{m}^{3}$ por dia e $127,20 \mathrm{~m}^{3}$ por mês.

\begin{tabular}{|c|c|c|c|c|}
\hline $\begin{array}{l}\text { Etapas da } \\
\text { limpeza }\end{array}$ & $\begin{array}{c}\text { Consumo de água antes } \\
\text { da implementação por } \\
\text { dia }\end{array}$ & $\begin{array}{c}\text { Consumo de água } \\
\text { depois da } \\
\text { implementação por dia }\end{array}$ & $\begin{array}{c}\text { Consumo de água antes } \\
\text { da implementação por } \\
\text { Mês }\end{array}$ & $\begin{array}{c}\text { Consumo de água depois } \\
\text { da implementação por } \\
\text { Mês }\end{array}$ \\
\hline Tubulações & $1 \mathrm{~m}^{3}$ por dia & $0,2 \mathrm{~m}^{3}$ por dia & $26 \mathrm{~m}^{3}$ & $0,2 \mathrm{~m}^{3} \times 26=5,2 \mathrm{~m}^{3}$ \\
\hline Envase & $2,5 \mathrm{~m}^{3}$ por dia & $0,5 \mathrm{~m}^{3}$ por dia & $65 \mathrm{~m}^{3}$ & $0,5 \mathrm{~m}^{3} \times 26=13 \mathrm{~m}^{3}$ \\
\hline Lavagem tanques & $20,85 \mathrm{~m}^{3}$ por dia & $0,26 \mathrm{~m}^{3} \times 16=4,16 \mathrm{~m}^{3}$ & $542 \mathrm{~m}^{3}$ & $4,16 \mathrm{~m}^{3} \times 26=109 \mathrm{~m}^{3}$ \\
\hline $\begin{array}{c}\text { Consumo total } \\
\mathrm{H}^{20}\end{array}$ & $24,85 \mathrm{~m}^{3}$ & $4,86 \mathrm{~m}^{3}$ & $633 \mathrm{~m}^{3}$ & $127,2 \mathrm{~m}^{3}$ \\
\hline Tempo gasto & $1: 40 \mathrm{~h}$ & 0:20 h & $43,20 \mathrm{~h}$ & 8: $40 \mathrm{~h}$ \\
\hline
\end{tabular}

Quadro 11 - Comparativo do tempo gasto e do consumo e água.

Fonte: Dados dos autores.

Essa economia ocorreu devido a melhorias no sequenciamento de produção e pequenas mudanças no layout da manufatura, de forma que os primeiros produtos fabricados não afetariam a qualidade dos próximos. Por exemplo: primeiro, são fabricados os produtos de aparência límpida ou sem cheiro, depois os que levam corantes ou perfumes em sua formulação.

Esse sequenciamento foi estabelecido primeiro para todos os produtos ácidos, sendo seguido pelos cáusticos, lubrificantes e detergentes. Isso também possibilitou a eliminação do processo de limpeza entre um produto e outro, obtendo-se considerável economia no uso da água. Portanto, a economia de água utilizada para a lavagem dos tanques, tubulações e envase foi de $505 \mathrm{~m}^{3}$ por mês $\left(633 \mathrm{~m}^{3}\right.$ mês $-127,2 \mathrm{~m}^{3}$ mês $)$ e de tempo foi de $43 \mathrm{~h} 20$ para $8 \mathrm{~h} 40$ por mês. Com a economia de água e de tempo, o PCP passou a programar seis bateladas por dia, aumentando a produtividade, totalizando 156 bateladas no mês, 26 bateladas a mais do que antes da implementação do projeto. Cada tanque de produção tem capacidade de água de $17,95 \mathrm{~m}^{3}$.
É importante ressaltar que o consumo de energia elétrica deveria ter aumentado de $5.125,375 \mathrm{kWh}$ para 6.150,45 kWh, considerando cada batelada medida no campo com um gasto de 39,43 kWh; porém, com a instalação das bombas trifásicas com selo Procel, com os inversores de energia e com os equipamentos de controle numérico, foi possível reduzir o consumo de energia para 4.305,315 kWh, em que cada batelada passou a ter um gasto de 27,60 kWh. Assim o PCP passou a utilizar melhor a sua capacidade produtiva. Outro ponto que merece destaque é a economia de água da natureza, que equivale a $269,60 \mathrm{~m}^{3}, \mathrm{R} \$ 2,68$ por $\mathrm{m}^{3}$, totalizando $\mathrm{R} \$ 722,53$.

\section{Vantagens econômicas e ambientais na implementação do projeto}

Nesta seção são apresentadas as vantagens econômicas e ambientais que a empresa química conquistou ao considerar o Planejamento da Produção com Educação Ambiental. Um aspecto relevante é que, o setor de PCP, após inserir a Educação Ambiental de maneira transversal, mudou o enfoque concomitantemente 
ao crescimento econômico e ao ganho ambiental nas ações de planejamento, programação e controle da produção, possibilitando considerar a produção mais limpa como novo objetivo de desempenho. Para isso, inseriu algumas ferramentas de gestão fundamentada no Centro Nacional de Tecnologias Limpas - CNTL, possibilitando elencar indicadores de desempenho para o controle do processo, tais como: (i) indicador econômico; (ii) indicador ambiental - Wuppertal; (iii) ênfase na metodologia de RH; e (iv) quantidade de projetos sustentáveis sugeridos. Dessa forma, primeiro serão apresentadas as vantagens econômicas e ambientais "Lean and Green", depois, a implementação de indicadores de desempenho para o monitoramento do projeto e, por fim, pretende-se estender os conceitos de produção mais limpa e Educação Ambiental para a rede de suprimentos com o foco no P\&D de produtos ecologicamente corretos.

\section{Vantagens "Lean and Green" e vantagens econômicas da implementação do projeto}

Com o aumento de uma batelada a mais por dia, 156 bateladas passaram a ser produzidas no mês, ocasionando um aumento de 17 pontos percentuais de produção, em consequência, conforme o Quadro 12, da redução nos custos em 18\% de hora/homem, que refletiu diretamente nos custos de produção. Sobre os custos de produção é possível perceber claramente que o projeto reduziu os gastos, depois de implementado, em R \$ 5.977,82.

\begin{tabular}{|c|c|c|c|c|c|c|c|c|}
\hline $\begin{array}{c}\text { Implemen- } \\
\text { tação do } \\
\text { projeto }\end{array}$ & $\begin{array}{l}\text { Consumo } \\
\text { de água } \\
\text { em me } \\
\text { em R\$ }\end{array}$ & $\begin{array}{c}\text { Produto } \\
\text { químico } \\
\text { Soluto+ } \\
\text { Solúvel } \\
\text { Densidade } \\
1,2 \\
\end{array}$ & $\begin{array}{c}\text { Custo em } \\
\text { R\$ da } \\
\text { água na } \\
\text { limpeza } \\
\text { dos } \\
\text { tanques } \\
\end{array}$ & $\begin{array}{c}\text { Consumo } \\
\text { de Energia } \\
\text { elétrica em } \\
\text { kWh e em } \\
\text { R\$ }\end{array}$ & $\begin{array}{c}\text { Custo hora homem } \\
\text { (Total de 30) R\$ } \\
1100,00 \text { + encargos }\end{array}$ & $\begin{array}{c}\text { Custo de } \\
\text { produção } \\
\text { por batelada }\end{array}$ & $\begin{array}{l}\text { Tempo de } \\
\text { produção }\end{array}$ & $\begin{array}{c}\text { Tempo de } \\
\text { lavar os } \\
\text { tanques }\end{array}$ \\
\hline Antes & $\begin{array}{l}3197 \mathrm{~m}^{3} \\
\mathrm{R} \$ \\
8.567,96\end{array}$ & $2799,6 \mathrm{~m}^{3}$ & $\begin{array}{c}\mathrm{R} \$ \\
1.759,74\end{array}$ & $\begin{array}{c}5.125,375 \\
\mathrm{kWh} \\
\mathrm{R} \$ 3.333,30\end{array}$ & $\begin{array}{c}1100 \text { X 30: 164,57 } \\
\text { (tempo de } \\
\text { produção) = R\$ } \\
\mathbf{2 0 0 , 5 2} \mathbf{C H H}\end{array}$ & $\begin{array}{c}\mathrm{R} \$ \\
7.154 .533,30: \\
130=\mathrm{R} \$ \\
55.034,00\end{array}$ & $\begin{array}{c}130 \\
\text { bateladas } \\
164: 34 \mathrm{~h}\end{array}$ & $43: 20 \mathrm{~h}$ \\
\hline Depois & $\begin{array}{c}2927,40 \\
\mathrm{~m}^{3} \\
\mathrm{R} \$ \\
7.845,43 \\
\end{array}$ & $\begin{array}{c}3360,24 \\
\mathrm{~m}^{3}\end{array}$ & $\mathrm{R} \$ 340,89$ & $\begin{array}{c}4305,315 \\
\text { kWh } \\
\mathrm{R} \$ 2.799,97\end{array}$ & $\begin{array}{c}1100 \text { X 30: 199,33 } \\
\text { (tempo de } \\
\text { produção) }=\mathbf{R} \$ \\
\mathbf{1 6 5 , 5 5} \mathbf{C H H}\end{array}$ & $\begin{array}{c}\mathrm{R} \$ \\
7.652 .763,90: \\
156=\mathrm{R} \$ \\
49.056,18\end{array}$ & $\begin{array}{c}156 \\
\text { bateladas } \\
199: 20 \mathrm{~h}\end{array}$ & $8: 40 \mathrm{~h}$ \\
\hline $\begin{array}{l}\text { Lean and } \\
\text { green }\end{array}$ & $\begin{array}{c}\text { Redução } \\
\text { nos custos } \\
\text { (R\$ } \\
\text { 722,53) e } \\
\text { redução no } \\
\text { consumo } \\
\text { de água } \\
\text { em } \mathbf{2 6 9 , 6} \\
\mathbf{m}^{\mathbf{3}}\end{array}$ & $\begin{array}{l}\text { Aumento } \\
\text { de } \\
\text { Produção } \\
\text { em } 17 \%\end{array}$ & $\begin{array}{c}\text { Redução } \\
\text { de custo } \\
\mathrm{R} \$ 722,53\end{array}$ & $\begin{array}{c}\text { Redução } \\
\text { nos custos } \\
\text { em R\$ } \\
533,33 \text { e } \\
\text { redução no } \\
\text { consumo de } \\
\text { EE em } \\
\mathbf{8 2 0 , 0 6} \\
\mathbf{k W h}\end{array}$ & $\begin{array}{c}\text { Redução do custo } \\
\text { hora homem em } \\
18 \%\end{array}$ & $\begin{array}{l}\text { Redução do } \\
\text { custo em } \\
\mathrm{R} \$ 5.977,82\end{array}$ & $\begin{array}{c}\text { Aumento } \\
\text { de } \\
\text { capacidade } \\
\text { produtiva } \\
34: 77 \text { h e } \\
\text { mais } 26 \\
\text { bateladas }\end{array}$ & $\begin{array}{c}\text { Redução } \\
\text { do tempo } \\
\text { em } 34: 30 \text { h } \\
\text { de } \\
\text { ociosidade }\end{array}$ \\
\hline
\end{tabular}

Quadro 12 - Vantagens "Lean and Green" mensais na implementação do projeto Fonte: Dados dos autores.

No Quadro 13 é possível verificar que, com o aumento da produção em $17 \%$, consecutivamente reduziu o custo do produto por litro produzido de $\mathrm{R} \$ 2,55$ para $\mathrm{R} \$ 2,28$. 


\begin{tabular}{|c|c|}
\hline Antes - Mensalmente & Depois - Mensalmente \\
\hline $\begin{array}{c}\text { Mo direta - } 30 \text { (func.) } x \mathrm{R} \$ 1100,00+80 \% \text { (salário + encargos } \\
\text { sociais) }=\mathrm{R} \$ 59.400,00\end{array}$ & Mo direta $=\mathrm{R} \$ 59.400,00$ \\
\hline $\begin{array}{c}\text { Mo indireta - } \mathrm{R} \$ 12.000,00 \text { (gerente) }+\mathrm{R} \$ 5.000,00 \text { (supervisor) } \\
+\mathrm{R} \$ 3200,00 \text { (encarregado) }+\mathrm{R} \$ 8.600,00(4 \text { Ass. } \mathrm{ADM})=\mathrm{R} \$ \\
28.800,00\end{array}$ & Mo indireta $=\mathrm{R} \$ 28.800,00$ \\
\hline $\begin{array}{c}\text { Matéria Prima - R } \$ 8.567,96 \text { (água) + } \mathrm{R} \$ 2.491 .432,10 \text { (soluto) } \\
+\mathrm{R} \$ 3.333,30 \text { (Energia Elétrica) = } \mathrm{R} \$ 2.503 .333,30 .\end{array}$ & $\begin{array}{c}\text { Matéria Prima }=R \$ 7.845,43 \text { (água) }+R \$ 2.989 .718,50(\text { soluto })+R \$ \\
2.799,97(\text { Energia Elétrica })=R \$ 3.000 .363,90\end{array}$ \\
\hline Transporte $-\mathrm{R} \$ 1.560 .000,00$ & Transporte $-\mathrm{R} \$ 1.560 .000,00$ \\
\hline Custo de Armazenagem - R $\$ 2.000 .000,00$ & Custo de Armazenagem - $\mathrm{R} \$ 2.000 .000,00$ \\
\hline Depreciação de máquinas - $\mathrm{R} \$ 3.000,00$ & Depreciação de máquinas - $\mathrm{R} \$ 3.000,00$ \\
\hline Equipamentos em comodato - R $\$ 1.000 .000,00$ & Equipamentos em comodato - R $\$ 1.000 .000,00$ \\
\hline Somatório (Custo de produção) $=\mathrm{R} \$ 7.154 .533,30$ & Somatório (Custo de produção) $=\mathrm{R} \$ 7.651 .563,90$ \\
\hline Produção $=2.799 .600$ litros & Produção $=3.360 .240$ litros \\
\hline Custo do produto $=\mathrm{R} \$ 2,55$ & Custo do produto $=\mathrm{R} \$ 2,28$ \\
\hline
\end{tabular}

Quadro 13-Comparativo dos custos por litro do produto.

Fonte: Dados dos autores.

Com a implementação do projeto foi possível concluir (Quadro 14) que houve uma redução no custo do produto em $\mathrm{R} \$ 0,27$ por litro; por questões de mercado o preço foi mantido, assim a empresa passou a ter um ganho de $22 \%$, além do aumento da capacidade de produção em $17 \%$. Somando-se, financeiramente, ocorreu um aumento de $\mathrm{R} \$$ 5.966.507,00.

\begin{tabular}{|c|c|c|c|}
\hline $\begin{array}{c}\text { Implementação do } \\
\text { projeto }\end{array}$ & Custo do litro & Faturamento por litro & Faturamento mensal \\
\hline Antes & $\begin{array}{c}\mathrm{R} \$ 7.154 .533,30: 2.799 .600 \text { litros }= \\
\mathrm{R} \$ 2,55\end{array}$ & $\mathrm{R} \$ 2,55+80 \%=\mathrm{R} \$ 4,59$ & $\begin{array}{c}2.799 .600 \text { litros } x \mathrm{R} \$ 4,59=\mathrm{R} \$ \\
12.850 .164,00\end{array}$ \\
\hline \multirow[t]{2}{*}{ Depois } & $\begin{array}{c}\mathrm{R} \$ 7.651 .563,90: 3.360 .240 \text { litros }= \\
\mathrm{R} \$ 2,28\end{array}$ & $\begin{array}{c}\mathrm{R} \$ 2,28+102 \%=\mathrm{R} \$ \\
4,59\end{array}$ & $\begin{array}{c}3.360 .240 \text { litros } \times \mathrm{R} \$ 4,59+22 \%=\mathrm{R} \$ \\
18.816 .671,00\end{array}$ \\
\hline & & $\begin{array}{l}\text { Mantém se o preço do } \\
\text { mercado aumenta os } \\
\text { ganhos em } 22 \%\end{array}$ & $\begin{array}{c}\text { Aumento dos ganhos financeiros em } \\
\text { R } \$ \mathbf{5 . 9 6 6 . 5 0 7 , 0 0}\end{array}$ \\
\hline
\end{tabular}

Quadro 14 - Redução no custo do produto e vantagem econômica.

Fonte: Dados dos autores.

\section{Vantagens ambientais}

Neste tópico são apresentadas as vantagens ambientais. São considerados como materiais todos os produtos que não são dispensados no meio ambiente de maneira negligente, incluindo a economia de água e de energia elétrica. Por meio dessa ação o impacto ambiental foi reduzido. A empresa informou o total de Massa em Material (MM) por mês que foi economizado: 269.600 litros de água e $820,06 \mathrm{kWh}$ por mês. Para determinar a Intensidade de Material, o fluxo de entrada de massa (expresso nas unidades correspondentes) é multiplicado pelo fator MIF (mass intensity factors), que corresponde à quantidade de matéria necessária para produzir uma unidade de fluxo de entrada. Os valores de MIF usados no presente trabalho estão na Tabela 1. Por exemplo: MM* MIF.

A Tabela 2 mostra a representatividade da economia de 4.885,56 de materiais no compartimento abiótico, isto é, contribui com a sustentabilidade no que tange ao aquecimento global, o desgaste da camada de ozônio, a pressão atmosférica, etc. Além disso, deixa de poluir a água com $381560,27 \mathrm{Kg}$ e o ar com 794,44 Kg. 
Tabela 2 - Vantagens ambientais conquistados na implementação do projeto.

Fatores de Intensidade de Material

\begin{tabular}{|c|c|c|c|c|}
\hline & Material abiótico & Material biótico & Água & $\mathbf{A r}$ \\
\hline Água potável $(\mathrm{L})^{\mathrm{a}}$ & 2696 & & 350480 & 269.60 \\
\hline $\begin{array}{c}\text { Energia elétrica } \\
\text { industrial }(\mathrm{kWh})^{\mathrm{b}}\end{array}$ & 2189,56 & & 31080,27 & 524,84 \\
\hline Total & 4885,56 & & 381560,27 & 794,44 \\
\hline & & & MTC & 387240,27 \\
\hline
\end{tabular}

Fonte: Dados dos autores.

Medidas de desempenho para melhorias processo (Quadro 15), que são: (i) ênfase na contínuas

metodologia de RH; (ii) indicador econômico; (iii)

Entre o sétimo e o oitavo meses, o ecotime elencou os indicadores de desempenho para o controle do indicador ambiental - Wuppertal; e (iv) quantidade de projetos sustentáveis sugeridos.

\begin{tabular}{|c|c|}
\hline Indicadores & Objetivo/ Meta \\
\hline (i) Ênfase na metodologia de RH & $\begin{array}{l}\text { Visa sensibilizar e disseminar a educação ambiental para funcionários } \\
\text { entrantes. }\end{array}$ \\
\hline $\begin{array}{l}\text { - Avaliação do desempenho de } \\
\text { aprendizagem. (Quantitativo). }\end{array}$ & $\begin{array}{l}\text { Mínimo } 85 \% \text { na nota, sendo } 30 \% \text { pela participação das aulas e } 70 \% \text { a nota do } \\
\text { teste com vinte questões. }\end{array}$ \\
\hline $\begin{array}{l}\text { - Reforço do direcionamento } \\
\text { estratégico no processo de } \\
\text { sensibilização de educação ambiental. } \\
\text { (Qualitativo). }\end{array}$ & $\begin{array}{l}\text { - Princípios - formação de disseminadores sobre práticas ambientais no sistema } \\
\text { produtivo; } \\
\text { - Propósito - treinamento e capacitação do diretor de supply chain, dois } \\
\text { planejadores e os } 180 \text { funcionários operacionais; } \\
\text { - Poder - sensibilização dos envolvidos para delegar e responsabilizá-los; } \\
\text { - Processos e prática - ensinar na teoria e na prática analisar os processos da } \\
\text { manufatura por meio da ferramenta de produção mais limpa e metodologia } \\
\text { wuppertall para avaliar a redução do impacto ambiental resultantes das ações } \\
\text { realizadas. }\end{array}$ \\
\hline $\begin{array}{l}\text { - Projeção de estender a educação } \\
\text { ambiental para a rede de suprimentos. } \\
\text { (Qualitativo e Quantitativo). }\end{array}$ & $\begin{array}{l}\text { Objetiva capacitar as camadas de fornecimento e os clientes sobre o P\&D de } \\
\text { produto ecologicamente correto. Pretende-se avaliar o desempenho da } \\
\text { aprendizagem da mesma maneira que avalia os funcionários. }\end{array}$ \\
\hline idores eco & onômicas. \\
\hline $\begin{array}{l}\text { - estudo de tempos e métodos dos } \\
\text { processos. (Qualitativo). }\end{array}$ & s a fim \\
\hline $\begin{array}{l}\text { - redução de custo hora homem. } \\
\text { (Quantitativo). }\end{array}$ & $\begin{array}{l}\text { hora de trabalho) - Quanto } \mathrm{r} \\
\text { homem. }\end{array}$ \\
\hline $\begin{array}{l}\text { - aumento de } \quad \text { produção. } \\
\text { (Quantitativo). }\end{array}$ & aumentar a quantidade produzida. \\
\hline $\begin{array}{l}\text { - redução de custos de produção. } \\
\text { (Quantitativo). }\end{array}$ & $\begin{array}{l}\text { to de energia - } \\
\text { rodução }\end{array}$ \\
\hline $\begin{array}{l}\text { - redução no custo do produto. } \\
\text { (Quantitativo). }\end{array}$ & $\begin{array}{l}\text { - Em detrimento da redução do custo de produção é possível reduzir o custo do } \\
\text { produto. }\end{array}$ \\
\hline $\begin{array}{l}\text { (iii) Indicadores ambientais - } \\
\text { Intensidade de material - MIF. } \\
\text { (Quantitativo) }\end{array}$ & $\begin{array}{l}\text { Visa avaliar os ganhos ambientais em detrimento ao reuso, reciclagem, } \\
\text { remanufatura. }\end{array}$ \\
\hline $\begin{array}{l}\text { (iv) Projetos } \quad \text { sustentáveis. } \\
\text { (Quantitativo). }\end{array}$ & $\begin{array}{l}\text { Visa avaliar a quantidade de projetos sustentáveis sugeridos e aceitos por } \\
\text { trimestre. }\end{array}$ \\
\hline
\end{tabular}

Quadro 15 - Indicadores de desempenho para o controle do processo visando melhorias.

Fonte: Dados dos autores. 


\section{Estender os conceitos de $P+L$ e educação ambiental para a rede de suprimentos}

A empresa química tende a estender os conceitos de produção mais limpa e Educação Ambiental para a rede de suprimentos nos próximos anos. Para isso, irá planejar e desenvolver produtos ecologicamente corretos, com o objetivo de verificar o ciclo de vida dos produtos, a fim de verificar a possibilidade de encontrar componentes substitutos que tenha menor impacto ambiental. Um aspecto relevante da análise do ciclo de vida é analisar as fontes de fornecimento, visando à homologação de fornecedores com certificação da qualidade ISO 14001:2004, que inclui a avaliação in locus sobre: reciclagem, reuso, remanufatura no sistema produtivo em ciclo fechado.

\section{Considerações Finais}

Neste artigo buscou-se enfatizar uma discussão mais profunda do tema e a qualificação dos profissionais do PCP, para que se tornem os gestores desse novo modelo (PPCPEA), podendo tomar decisões mais assertivas frente à sustentabilidade.

Para isso, a alta administração da empresa química de transformação decidiu entronizar a Educação Ambiental nas ações operacionais, considerando de suma importância, antes da implementação da $\mathrm{P}+\mathrm{L}$, sensibilizar os 180 funcionários, diretor de supply chain e dois planejadores da produção.

Em um primeiro momento decidiu-se contratar dois professores/consultores do Serviço Nacional de Atividade Industrial - SENAI para gerenciar o processo e capacitar os envolvidos em educação ambiental. O tema Educação Ambiental foi discutido de maneira transversal em todos os dias de aprendizagem, visando motivar o envolvimento e ação do ser humano na resolução de problemas ambientais.

As aulas foram ministradas nos dois meses iniciais e, ao final, selecionaram-se 33 funcionários para compor o ecotime. Esses funcionários selecionados tiveram desempenho igual ou superior a 85 no que tange à aprendizagem.

A partir daí o ecotime, com o apoio da alta administração, desenvolveu plano de ação com dez prioridades para serem cumpridas em mais seis meses, que visam: retransmitir os conceitos sobre Educação Ambiental e produção mais limpa para 150 funcionários reprovados, desenvolver infraestrutura e estrutura para a implementação do projeto Minimization (sequenciamento de cargas), com o objetivo de analisar o sistema produtivo e elaborar o balanço material para verificar ganhos econômicos e ambientais oriundos da redução de consumo de água, energia elétrica, aumento da produção e redução de custos operacionais. Além disso, foi possível implementar medidas de desempenho com ênfase na metodologia de recursos humanos, visando principalmente à sensibilização sobre Educação Ambiental, indicadores econômicos e ambientais e mensurar a quantidade de projetos sustentáveis sugeridos.

É importante salientar que os dois planejadores de produção foram os principais agentes do ecotime para desenvolver o detalhamento do plano de ação, devido à visão holística do processo. Segundo os planejadores, no momento da sensibilização e disseminação, eles já refletiram nos pontos de melhorias ambientais no sistema produtivo, por conhecerem o processo. Dessa forma, considera-se a temática do modelo "PCP com Educação Ambiental" como inovação na literatura, aplicada após a publicação do modelo em 2010. Tambémé importante ressaltar que a P+L está intrínseca em todo o processo, como consta do modelo, mas que a implementação da mesma só foi possível após a sensibilização e disseminação da Educação Ambiental de maneira transversal entre os envolvidos.

Nesse projeto Minimization (Sequenciamento de Cargas) ocorreu uma economia de 270.420,06 Kg por ano (soma bruta dos materiais) e representa $387.240,27 \mathrm{Kg}$ de materiais de todos os compartimentos (MTC) que não são retirados do meio ambiente. Os ganhos lean com a otimização da capacidade produtiva resultaram em aumento de $17 \%$ da produção, redução dos custos de produção e, consecutivamente, redução no custo do produto por litro produzido, que impulsionaram a aumento da 
lucratividade de $\mathrm{R} \$ 5.966 .507,00$. Calculando a relação (Material Economizado (ME)/Dinheiro Economizado (DE)), muda de 0,05 , considerando só os materiais reaproveitados, para 0,06 , quando são considerados os materiais de todos os compartimentos (MTC). No primeiro caso, cada real economizado corresponde a 0,05 de material. Quando se considera a escala global, por cada real, há um beneficio de 0,06 de material, que não é modificado nem retirado dos ecossistemas. Os resultados apontam para um ganho da organização, que teve aumentada sua capacidade produtiva em $17 \%$, reduzido o custo da mão de obra direta em $18 \%$ e uma vantagem ambiental maior em 0,01 de materiais, correspondendo ao material que não é modificado nem retirado dos ecossistemas.

Os benefícios ambientais podem ser avaliados quantitativamente usando uma metodologia adequada. Isso permite acompanhar o desempenho da empresa. É possível obter informações em escala global confrontando aspectos ambientais e financeiros. Os resultados apresentados na discussão e conclusão são satisfatórios para a empresa em estudo: de um lado a organização adquire vantagens econômicas e, de outro, vantagens ambientais, favorecendo a competitividade empresarial.

\section{REFERÊNCIAS}

AZZOLINI, W.J. Tendências do processo de evolução do sistema de administração da produção. f.293. Tese de Doutorado em Engenharia de Produção. Universidade de São Paulo - USP. EESC - Escola de Engenharia de São Carlos. 2004.

BARBIERI, J.C; SILVA, D. Desenvolvimento sustentável e educação ambiental: uma trajetória comum com muitos desafios. RAM, VER. ADM Mackenzie, v.12, n.3, p. 51-82. 2011.

BOGDAN, R.; BIKLEN, S. Qualitative

Research for Education: an Introduction to Theory and Methods. 2.ed. Boston: Allyn and Bacon, 1992.
BOWEN, F.; COUSINS, P.; LAMMING, R.; FARUK, A. The role of supply management capabilities in green supply. Production an Operations Management, v. 10, n.2, p. 174-89, 2001.

BOOTH, R. Agile Manufacturing. Engineering Management Journal, v. 6, n.2, p.105-112, 1996.

BLACKBURN, J.; "The time factor", In:

BLACKBURN, J. (Editor) Time-based

Competition - The next Battleground in Manufacturing, Business One Irwin, Homewood, IL, 1991a. p. 3-23.

BUFA, E.S. Meeting the competitive Challenge. Irwin: Homewood (IL), 1984.

CONTADOR, J.C. Campos e armas da competição: novo modelo de estratégia. São Paulo: Saint Paul Editora, 2008.

DENZIN, N. K. \& LINCOLN, Y. S. Handbook of Qualitative Research. Thousand Oaks: Sage, 2005.

DE VOR, R.; GRAVES, R.; MILLS J.J. Agile manufacturing research: accomplishments and opportunities. IIE Transation, v. 29, p. 813-823, 1997.

\section{DOSI, G. Mudança Técnica e transformação} industrial: a teoria e uma aplicação à indústria dos semicondutores. Campinas: Editora da Unicamp, 2006.

EISENHARDT, K. M. Building Theories from Case Study Research. Academy of Management Review, v. 14, n. 4, 1989. p. 522-550.

FURTADO, J.S. Sustentabilidade Empresarial: Guia de práticas econômicas, ambientais e sociais. Bahia: NEAMA/CRA, 2005. 
GODINHO FILHO, M. Paradigmas Estratégicos de Gestão da Manufatura: configurações, relações com o planejamento e controle da produção e estudo exploratório na indústria de calçados. Tese (Doutorado em Engenharia de Produção) - Universidade Federal de São Carlos: São Carlos, 2004.

GOLDHAR, J. D.; JELINEK, M. Plan for economies of scope. Harvard Business Review, v.61, n.6, p.141-148, nov./dec. 1983.

GUNASEKARAN, A. Agile manufacturing: A framework for research and development.

International Journal of Production Economics, v. 62, p. $87-105,1999$.

HANDFIELD, R. B. \& PANNESI, R. T. Antecedents of lead time competitiveness in make to order manufacturing firms. International Journal of Production Research, v. 41, n.4, p. 511-537, 1995.

HAYATI, D; KARAMI, E. \& SLEE, B. Combining qualitative and quantitative methods in the measurement of rural poverty. Social Indicators Research, v.75, p.361-394, 2006.

\section{INTERGOVERNMENTAL COFERENCE ON}

EE. Final report. Retrieved May 11, 2008 from http;/unesdoc.unesco.org/images/0003/000327/ 032763eo.pdf, 1977. Acesso em junho de 2009.

KYBURZ-GRABER, R; HEFFER, K \& WOLFENSBERGER, B. Studies on a socioecological approach to EE: Acontribution to a critical position in the education for sustainable development discourse. EE Research, n.12, p. 101-114, 2006.

NBR ISO 14001:2000. Associação brasileira de Normas técnicas. Rio de Janeiro: ABNT: 2003.

NEVENS, F., DESSEIN, J., MEUL, M., ROGGE,
E., VERBRUGGEN, I., MULIER, A., PASSEL, S.V., LEPOUTRE,J., HONGENAERT, M. On tomorrow's grounds. Flemish agriculture in 2030: a case of participatory translation of sustainability principles into a vision for the future. Journal of Clean Production. n.16, p.1062-1070, 2008.

NEVES, J. L. Pesquisa qualitativa: características, usos e possibilidades. Cadernos de Pesquisas em Administração, v. 1, n.3, 2º sem., 1996.

NIELSEN, S.N.; MULLER, F. Understanding the functional principles of nature-proposing another type of ecosystem services. Ecological Modeling, v., n., p.1913-1925, 2009.

ODUM, E.P., Ecologia. Rio de Janeiro: Guanabara Koogan SA, 1998.

OLIVEIRANETO, G.C; AZZOLINI JUNIOR; Walther; BONILLA, Silvia. H. Do avanço do Planejamento, programação e Controle da Produção como atividades essenciais da empresa à educação ambiental. Revista Uniara, v. 13, n.1, jul. 2010.

OLIVEIRANETO. G.C; LOPES. MA; KONISHI. F; SILVA. J.U. DA. Proposta de Governança do Conhecimento para a Sustentabilidade em Instituições do Ensino Superior: a busca de um futuro promissor. Rio de Janeiro: CNEG, 2009.

PEARSON EDUCATION DO BRASIL. Gestão ambiental. São Paulo: Person Prentice Hall, 2011.

PINE, B. J. Personalizando produtos e serviços: customização maciça. São Paulo: Makron Books, 1994.

PORTO, A.J.V; SACOMANO, J.B; AZZOLINI JR, W.Tendências do sistema de gestão da produção quanto às habilidades necessárias para enfrentar os desafios inerentes à estratégia competitiva. ENCONTRO NACIONAL DE 
ENGENHARIA DE PRODUCÃO, 24, 2004, Florianópolis. Anais. Florianópolis: ENEGEP, 2004.

SEIDMAN, I. E. Interviewing as Qualitative Research. A Guide for Researchers in Education and the Social Sciences. New York: Teachers College/Columbia University Press, 1991.

SENAI. Implementação de Programas de Produção mais Limpa. Porto Alegre: Centro Nacional de Tecnologias Limpas SENAI-RS/ UNIDO/INEP, 2003.

SHARIFI, H. \& ZHANG, Z. A methodology for achieving agility in manufacturing in the UK industry. International Journal of Production Economics, v. 62, p.7-22, 1999.

SHIN, D., CURTIS.,M., HUISING.,D., ZWETSLOOT, G.I. Development of a sustainability polity model for promoting cleaner production: a knowledge integration approach. Journal of Clean Production, n 16, p.18231837, 2008.

SLACK, NIGEL.; CHAMBERS, STUART,; JOHNSTON, ROBERT. Administração da
Produção. 2. ed. São Paulo: Atlas, 2007.

STRIFE, S. Reflecting on Environmental Education: Where Is Our Place in the Green Movement. The Journal of Environmental Education, v. 41, n.3, p. 179-191, 2010.

US EPA. The Lean and Green Supply Chain: A practical Guide for Materials Managers and Supply Chain Managers to Reduce Costs and Improve Environmental Performance, US: EPA, 2000.

WOMACK, J. P. \& JONES, D. T. A Mentalidade Enxuta nas Empresas. Rio de Janeiro: Campus, 5.ed. 1998.

WOMACK, J. P., JONES. D.T., ROOS,D. A máquina que mudou o mundo. Rio de Janeiro: Campus, 1992.

WUPPERTAL, Institute. Calculating MIPs, resources productivity of products and services. Available from: http://www.wupperinst.org/uploads/ tx_wiberitrag/MIT_v2.pdf; [accessed April 2008].

YUKSEL, H., Na empirical evaluation of clean production pratices in turkey. Journal of Clean Production, v. 16 p 50-57, 2007. 